\title{
Advances and perspectives in tissue clearing using CLARITY
}

\author{
Kristian H. Reveles Jensen ${ }^{1} \&$ Rune W. Berg ${ }^{2}$ \\ ${ }^{1}$ krijen@sund.ku.dk, ${ }^{2}$ runeb@sund.ku.dk \\ ${ }^{1,2}$ University of Copenhagen \\ Blegdamsvej 3B \\ 2200 Copenhagen \\ Denmark
}

July 12, 2017

\begin{abstract}
CLARITY is a tissue clearing method, which enables immunostaining and imaging of large volumes for $3 D$ reconstruction. The method was initially time-consuming, expensive and relied on electrophoresis to remove lipids to make the tissue transparent. Since then several improvements and simplifications have emerged, such as passive clearing (PACT) and methods to improve tissue staining. Here, we review advances and compare current applications with the aim of highlighting needed improvements as well as aiding selection of the specific protocol for use in future investigations.
\end{abstract}

\section{Keywords:}

CLARITY; tissue clearing; refractive index; brain; immunohistochemistry; histology; biocytin; virus; tracing

\section{Chemical compounds:}

Chemical compounds mentioned in this article: 1-Ethyl-3-(3-dimethylaminopropyl)carbodiimide (PubChem CID: 15908); 2,2'-Thiodiethanol (PubChem CID: 5447); $\alpha$-Thioglycerol (PubChem CID: 7291); Acrylamide (PubChem CID: 6579); D-Sorbitol (PubChem CID: 5780); Diatrizoic acid (PubChem CID: 2140); Gylcerol (PubChem CID: 753); Iohexol (PubChem CID: 3730); Iomeprol-d3 (PubChem CID: 46781978); N,N,N',N'-Tetrakis(2-Hydroxypropyl)ethylenediamine (amino alcohol, PubChem CID: 7615)

\section{Introduction}

The process of clearing tissue for the purpose of histological analysis has recently become a common tool in biological investigations. The purpose is to keep the proteins in a structure while removing the lightscattering lipids, and thus to allow deep penetration of light for fluorescent 3D microscopy. Several clearing methods have recently been developed.

Here, we focus on the advancement in the procedure called CLARITY ( $C$ lear Lipid-exchanged Acrylamidehybridized Rigid Imaging/Immunostaining/In situ-hybridization-compatible $T$ issue-h $Y$ drogel). It is a convenient histological fixation and clearing technique that enables immunohistochemistry (ICH) and maintenance of fluorophores during imaging of large volumes for 3D-reconstruction. The method was developed by Chung, Gradinaru, Deisseroth \& colleagues and relies on the removal of lipids while keeping the protein and DNA of the tissue by creating a hydrogel by cross-linking with acrylamide (Chung et al., 2013; Chung and Deisseroth, 2013). Since then several improvements and simplifications have emerged, such as passive 
clearing (PACT), and other adaptations (EDC-CLARITY).

We review advances, and compare current applications and limitations for this methodology, with the aim of highlighting needed improvements as well as aiding selection of the specific CLARITY or hydrogel-based protocol for use in future investigations. CLARITY was originally demonstrated on rodent brains, but has since been successfully applied to other tissues organs and species, e.g. fish and plants. In this review, we primarily focus on nervous tissue although the protocols work for other tissues as well.

\section{The original CLARITY method}

CLARITY works by polymerising proteins, DNA, and RNA in fixed tissue using acrylamide to form a tissue-hydrogel hybrid before lipid-removal. The acrylamide based hydrogel binds molecules with amine ends, predominantly proteins and a small proportion of DNA and RNA, into a skeleton structure, which is permeable to larger molecules. The lipids are then encapsulated into micelles using detergent (sodium dodecyl sulfate, SDS). The micelles are electrically charged and can therefore easily be carried out through the pores by an applied electrical field. Antibodies for immunohistochemistry (ICH) can also penetrate the hydrogel to reach and stain the fixed membrane proteins. The original protocol was first demonstrated on whole adult mice brains and can be summarised in the following steps:

1. Fixation of tissue. The animal is transcardially perfused with a mixture of $4 \%(\mathrm{w} / \mathrm{v})$ paraformaldehyde (PFA), $4 \%$ (w/v) acrylamide, $0.05 \%$ (w/v) bis-acrylamide, $0.25 \%(\mathrm{w} / \mathrm{v})$ VA-044 and in phosphatebuffered saline (PBS), and the brain is removed and incubated in the same solution for 3 days.

2. Hydrogel formation. A 3-hour heat activation at $37^{\circ} \mathrm{C}$ for the thermal initiator, VA-044, results in the polymerisation of the acrylamide and bis-acrylamide to the PFA-fixed tissue.

3. Lipid extraction. Tissue clearing, or lipid removal, is accomplished by incubating the tissue in a sodium borate buffer (0.2 M, pH 8.5) containing $4 \%(\mathrm{w} / \mathrm{v})$ SDS in a custom-designed electrophoretic chamber. The basic $\mathrm{pH}$ leads to negatively charged micelles, which pass trough the porous hydrogel by electrophoresis using a $10-60 \mathrm{~V}$ current applied across the sample at $37-50^{\circ} \mathrm{C}$ for two days.

4. Refractive index matching. The tissue is washed in PBS for two days to remove SDS. The tissuehydrogel has a refractive index (RI) of 1.44-1.46. The tissue is incubated with a proprietary imaging solution, FocusClear (CelExplorer Labs Co.), with a similar RI of 1.454 to increase transparency.

The novelty in the CLARITY method is the second step since utilization of a hydrogel had a clear benefit compared with other methods. Even using the harsh 4\% SDS for a week, the cleared tissue had only $8 \%$ protein loss. For comparison, in PFA-fixed tissue in $4 \%$ SDS, without the hydrogel up to $65 \%$ protein was lost. Similar protein loss is observed using other clearing methods without a hydrogel, such as Sca/e, which uses urea and glycerol (Hama et al., 2011). The effective retention of proteins and antigens also enabled repetitive staining, where antibodies could be washed out briefly in 4\% SDS and restained.

However, the step of lipid extraction had several limitations: active clearing with electrophoresis required a custom-designed chamber with a continuous exchange of SDS solution. The electrical current, if not properly controlled, can decompose or discolour the tissue. Thus, since the original CLARITY method both required expensive elements in step 4 such as the RIMS medium (FocusClear) and was difficult to implement, a potential for improvement presented itself. Several labs have employed a more simple version of CLARITY without electrophoresis, which is the passive CLARITY clearing. The need for cheaper refractive index imaging solutions than the original (FocusClear) has also become apparent. First, we will address the general challenges in tissue clearing.

\section{6}

CLARITY in its original form used electrophoretic tissue clearing (ETC) to extract lipids from large samples, which can be challenging to implement and can cause variability in final tissue quality, including epitope loss, damage to fine processes, and tissue browning due to heating (Lee et al., 2014). 


\section{General challenges}

There are several issues to consider when clearing tissue. Processing time, the number of procedural steps, the toxicity of reagents, signal and bleaching of fluorophores and the required concentration of primary and secondary antibodies, which are usually expensive and therefore beneficial to reduce. Efficiency in the extraction of lipids from the hydrogel, i.e. how much of the original lipids remain and how much time does the procedure require. Successful extraction of lipids is usually manifested in the transparency of the sample and the incubation time is often adjusted by the investigator for the sample to achieve the appropriate properties. Although the tissue transparency has been attributed to the removal of lipids during the procedure, it is still unknown to what extent the lipids are cleared from the sample and how much remains in transparent samples. This is contrary to the degree of protein loss, which has been quantified (Chung et al., 2013; Lai et al., 2016).

A major challenge introduced by clarified tissue samples is the imaging technology followed by the data analysis. Using conventional single photon laser scanning confocal microscopy, vast areas of the sample become unnecessarily illuminated, which introduces photobleaching of the fluorophores as a general issue. Photo-bleaching is potentially devastating in samples with a weak fluorescent signal, such as in Brainbow tissue (Cai et al., 2013).

For the same reason, it is important to limit the protein loss during storage of CLARITY samples. A novel imaging technology overcomes this issue by selectively only illuminating a single thin plane in a sequential manner. This technique is known as light-sheet microscopy, which can give a high rate of data acquisition of high contrast and resolution, and with very limited exposure to the rest of the sample (Stefaniuk et al., 2016). Light-sheet microscopy is remarkably faster than traditional single- or two-photon laser scanning microscopy. Several variants of light-sheet microscopy are commercially available, but they are not inexpensive and will represent a major investment to most laboratories. Another issue to consider is the price of the equipment and protocol compounds. The equipment necessary to set up active CLARITY with electrophoresis is approximately 6,800 USD. FocusClear is the originally recommended imaging media, which is expensive, but other less expensive alternative exist such as RIMS, sRIMS and glycerol.

It is also important to consider that acrylamide, the primary component in the formation of the hydrogel, is a carcinogenic compound and is on the U.S. federally regulated list of 'extremely hazardous substances'. Finding a less toxic alternative is therefore appealing. An acrylamide-free procedure with fewer steps has been suggested that the SDS alone can extract the lipids without the need for the toxic hydrogel (Lai et al., 2016).

Based on these issues, we have composed a list of improvements in the CLARITY protocol below.

\section{Variants and improvements of CLARITY}

The steps of the CLARITY procedure including staining and imaging is summarized as follows: 1) Tissue fixation and cutting, 2) Hydrogel polymerization, 3) Passive or active lipid removal, 4) Staining, 5) Optical clearing, 6) Imaging (figure 1). Here we summarize the improvements in these steps. A list of variants of the CLARITY improvements are found in table 3.

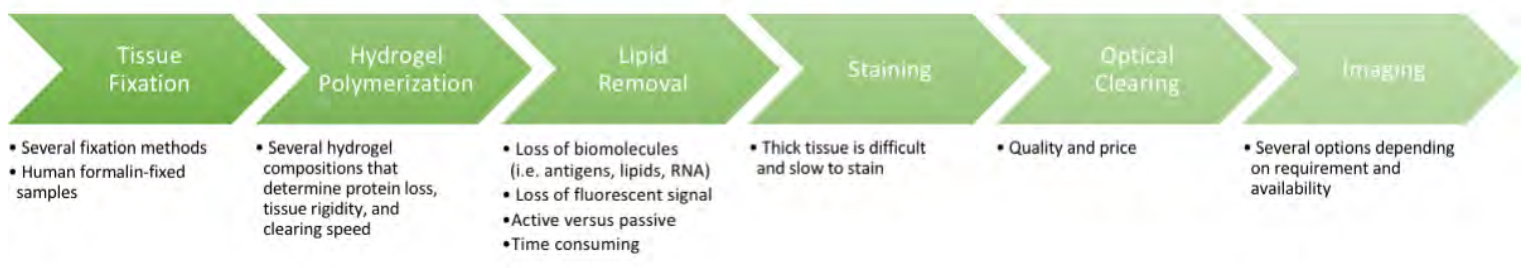

Figure 1: Steps in the CLARITY procedure including challenges and considerations. 


\section{Tissue fixation and cutting}

Tissue fixation is the initial step in practically all histology as well as CLARITY. The original protocol prescribes the animal to be transcardially perfused with $4 \%$ PFA together with the acrylamide monomers and activator VA-044, and the nervous tissue further incubated in the same solution for 3 days (Chung et al., 2013). In the following published protocol, the incubation was shortened to 1 day (Tomer et al., 2014). However, fixation with $4 \%$ PFA alone was later demonstrated as sufficient for the subsequent crosslinking and hydrogel polymerization if the tissue was just incubated in the monomer solution afterwards (Costantini et al., 2015; Lee et al., 2014; Zheng and Rinaman, 2016; Jensen and Berg, 2016). Transcardial perfusion of PBS to remove blood followed by the fixative or monomer solution is preferable. However, for some purposes just fixing the excised tissue, which has not been perfused, e.g. human tissue, overnight in $4 \%$ PFA in PBS is sufficient. Trimming the tissue down to the minimal required volume speeds up clearing and staining. Smaller tissue volume also results in less light scattering and clearer imaging. This can be done by embedding the tissue in low melting agar and cutting the tissue down to the most practical form e.g. a hemisphere, 1-2 mm slices or sections on a vibratome. Slicing the tissue after the hydrogel formation (step 2 ) is not recommended since the hydrogel swells to a sticky mass and is difficult to cut accurately, besides being carcinogenic. We recommend cutting before incubation and the polymerisation step.

\section{Hydrogel polymerization and composition}

Warning! Acrylamide is carcinogenic and should be handled with great care. After fixation, the tissue needs to be cross-linked and hybridised into a hydrogel by the acrylamide monomers to stabilise biomolecules and retain them during tissue clearing. The purpose is to achieve a fast and homogeneous clearing process, with good antibody penetration depth and retaining the desired antigens (protein). PFA fixes the tissue and supposedly acts as an anchor point for the acrylamide monomers to polymerise into a mesh. After removal of lipids the proteins are left in a hydrogel (step 3).

The original hydrogel monomer solution ( $4 \% \mathrm{PFA}, 4 \%$ acrylamide, $0.05 \%$ bis-acrylamide) was optimized to provide a balance between hydrogel rigidity and porosity with minimal protein loss $(\sim 8 \%$ when cleared in a 4\% SDS borate buffer) after ETC clearing (Chung et al., 2013). However, solution adjustments may be useful for applying CLARITY to certain kinds of tissues and passive and active clearing.

While an emphasis has been put on optimising the hydrogel composition for passive clearing, the modifications in the hydrogel composition are applicable to both passive and active clearing by electrophoresis. The hydrogel presented in the PACT method (the A4P0 composition) is the current default in for passive clearing, but it is also applied in active clearing with the ACT-PRESTO protocol. Others have used 2\%PFA and $2 \%$ acrylamide for active clearing (Bastrup and Larsen, 2017). The variations in the hydrogel monomer solution are therefore presented here before addressing the lipid extraction step.

\section{PACT and PARS}

Yang et al. (2014) focused on developing a simple version of CLARITY based purely on the passive removal of lipids, i.e. passive clearing. They tested several hydrogel compositions and SDS concentrations leading to an improved protocol named PACT (passive CLARITY technique) protocol. They had three main findings: First, omitting PFA in the monomer solution did not change the degree of protein loss, but did increase IgG penetration depth i.e. better antibody labelling. Second, omitting PFA leads to faster transparency, but also a greater tissue swelling $(\sim 230 \%)$, yet the swelling is transient, and may improve staining by making the tissue more porous. Finally, lower acrylamide concentration (i.e. 2\%) leads to less cross-linking and less solid tissue, this in turns results in faster clearing, but also greater tissue swelling and protein loss. Hence, they concluded that $4 \%$ acrylamide, which they referred to as A4P0 solution, is optimal for nervous tissue and other tissues e.g. liver and kidney.

While A4P0 was optimised for passive clearing, the recipe is also used in active clearing (Lee et al., 2016). Rather than tissue incubation in the monomer solutions, the PACT reagents can be delivered either via the vasculature (intracardial injection) or intracranially by injection into the cisterna magna or a subdural 
cannula above the olfactory bulb to achieve whole body or CNS clearing and labelling. The technique is termed PARS (Perfusion-assisted Agent Release in $S$ itu). The PACT reagents used in PARS are recirculated into the cerebrospinal fluid (CSF) or through the whole-body vasculature for several days-to-weeks in closedloop perfusion system mimicking regular blood flow allowing for clearing and staining deep in the tissue (Tomer et al., 2014). PARS does not change the speed of tissue clearing of the brain or internal organs (Woo et al., 2016), table 2. The PARS delivery system can be combined with other of the below methods if needed. In summary, PACT/PARS is a radical improvement since they provide a simpler recipe, which also gives a faster clearing with better antibody staining.

\section{psPACT}

psPACT (processes separate PACT) enhanced the clearing speed by splitting the monomer incubation into separate processes before polymerisation: an initial $24 \mathrm{hr}$ incubation at $37^{\circ} \mathrm{C}$ in acrylamide solution ( $4 \% \mathrm{w} / \mathrm{v}$ in PBS), followed by a $6-12 \mathrm{hr}$ incubation at room temperature in VA-044 initiator solution $(0.25 \%$ $\mathrm{w} / \mathrm{v}$ in PBS) for the hydrogel formation. This protocol shortens the subsequent clearing time by $\sim 10 \%$ (Woo et al., 2016). A comparison of protein loss with the PACT method has not yet been performed.

\section{ePACT}

ePACT (expansion-enhanced PACT) is used to expand thin tissue sections $(100 \mu \mathrm{m})$ to larger volumes for better resolution and resolution beyond the diffraction limit (Treweek et al., 2015). The hydrogel is composed of an acrylate-acrylamide copolymer and cleared with $10 \%$ SDS, where IHC such be done prior, and then digested with collagenase before incubation in water, which results in water absorption and tissue expansion.

\section{FASTClear}

In CLARITY protocols proteins are assumed to be fixed to an acrylamide scaffold via PFA, whereas lipids are washed out by the amphiphilic SDS-micelles. Nevertheless, Lai et al. (2016) demonstrated an acrylamidefree version of CLARITY, where the tissue is essentially only washing with SDS followed by RIMS, gave better results for formalin-fixed tissue. Therefore Lai et al. (2016) suggested that the tissue-PFA-acrylamide cross-linking does not actually occur, and therefore omitting acrylamide-polymerisation is not only easier, but also better. Hence, they developed a Free of acrylamide SDS-based tissue-clearing (FASTClear) protocol (Liu et al., 2016).

\section{Other modifications}

It is worth noting that the PACT protocol also omits bis-acrylamide, which acts as a secondary cross-linker, and therefore does not link the PFA-tagged biomolecules, but rather directly cross-links poly-acrylamide chains to form the gel. Therefore Bis-acrylamide increases the rigidity of the hydrogel network by creating cross-links inside cavities that may be void or sparse of biomolecules such as the ventricles. Bis-acrylamide also causes all the hydrogel solution surrounding the tissue sample to cross-link and form a gel during the polymerization step, which is a helpful aid in determining successful polymerisation. The surrounding gel can easily be removed manually from the tissue by physical rubbing/handling. Without bis-acrylamide and the gel formation outside the tissue, the sample can simply be removed from the solution following the polymerization step and is therefore recommended for small or fragile specimens that cannot withstand the physical gel removal process.

The incubation time of the tissue in monomer solution before polymerisation varies among authors with 1-3 days of incubation for a whole rodent brain, while for 1-2 mm slices overnight is sufficient. Saponin is a mild non-ionic surfactant often used to permeabilise cellular membranes in conventional histology. It was briefly mentioned by Chung and Deisseroth (2013) as an adjunct in the monomer solution to improve diffusion of the hydrogel monomer and initiator into tissues, where cardiac perfusion is not possible e.g. post-mortem human tissues and zebrafish brains. Saponin reportedly shortens the incubation time required in the hydrogel monomer infusion process. However, saponin may cause bubbles, and therefore it is not recommended 
and red has only been reported utilised in a study of ovarian follicles (Feng et al., 2017). In zebrafish adding dimethyl sulfoxide (DMSO) improves monomer penetration.

Another challenge for users has been initiating the polymerisation, which is inhibited by oxygen. The original CLARITY protocol, therefore, involved a vacuum desiccation chamber(Chung et al., 2013). While Yang et al. (2014) demonstrated it was sufficient to displace the oxygen from the solution by bubbling for $\sim 10$ min with Nitrogen gas before initiation. Some users have found it sufficient to prevent aeration by sealing the monomer solution off by placing a layer of vegetable oil on top in the test tube (forum.claritytechniques.org), yet others simply filled the tube entirely with the monomer solution to minimise inhibitory effects of the oxygen (Bastrup and Larsen, 2017). Another method simply uses double the concentration of the initiator, VA-044, which eliminates any vacuum purging or nitrogen backfilling. This method is called 'simplified CLARITY method' (or SCM), but was only tested on thin sections, of $100 \mu \mathrm{m}$ (Sung et al., 2016).

\section{Lipid removal}

Since membrane lipids are the main cause of light diffraction in tissues and comprise $\sim 60 \%$ of nervous tissue, lipid elution renders the tissue translucent. Temperature and solutions affect lipid clearing: speed, uniformity and protein loss. The original CLARITY protocol used a 4\% SDS (sodium borate buffer, $\mathrm{pH} 8.5$ ) intended for active clearing by electrophoresis (see below). Tissue clearing can be passive where lipids captured in detergent micelles slowly diffuse out of the tissue into the wash solution or active at an accelerated rate by applying an electric field (figure 2). In a study comparing active and passive CLARITY, there were no significant differences in protein concentration as an effect of active versus passive clearing (Epp et al., 2015).

\section{Passive lipid removal}

Passive clearing without electrophoresis is gentle on the tissue with little risk of damage. The clearing lasts longer, which can reduce the signal from fluorescent proteins and increase the loss of biomolecules. It is inexpensive and requires little equipment. A simplified diffusion-based method omitting the electrophoretic chamber, coined CLARITY2, to clarify $<1.5 \mathrm{~mm}$ thick slices was proposed by Poguzhelskaya et al. (2014) .

\section{PACT}

Yang et al. (2014) optimised the hydrogel composition for passive clearing and also tested several SDS concentrations leading to the improved PACT protocol. They found that $8 \%$ SDS (in PBS buffer, pH 7.5) gave a faster and more uniform tissue clearing compared to 4\% SDS, $20 \%$ SDS and $10 \%$ sodium deoxycholate. For this reason, PACT has become the default passive CLARITY protocol. There is no significant difference in the swelling and shrinking behaviour of passively cleared rodent gut tissue with CLARITY or PACT solution, nor a difference in clearing time (Neckel et al., 2016).

\section{mPACT}

Woo et al. (2016) was inspired by the SeeDB method (Ke et al., 2013) and added $0.5 \% \alpha$-thioglycerol to the PACT clearing solution, which improved clearing time with $\sim 10 \%$. They named it psPACT (processseperated PACT) with added $\alpha$-thioglycerol mPACT (modified PACT). The mPACT gives a combined $\sim 25 \%$ faster clearing compared with regular PACT on most tissues (table 2). The effect of $\alpha$-thioglycerol on protein loss has not been reported, but any protein loss is unlikely to have an adverse effect. On the contrary, since $\alpha$-thioglycerol preserves proteins by counteracting the Maillard reaction, i.e. browning of the specimen, autofluorescence and antigen loss is likely to be minimal.

\section{Temperature and speed}

Tissue clearing is often performed at room temperature (RT) or $37^{\circ} \mathrm{C}$. Generally, increasing temperature accelerates clearing and imaging depths but at the risk of damage to the tissue and quenching fluorescent 


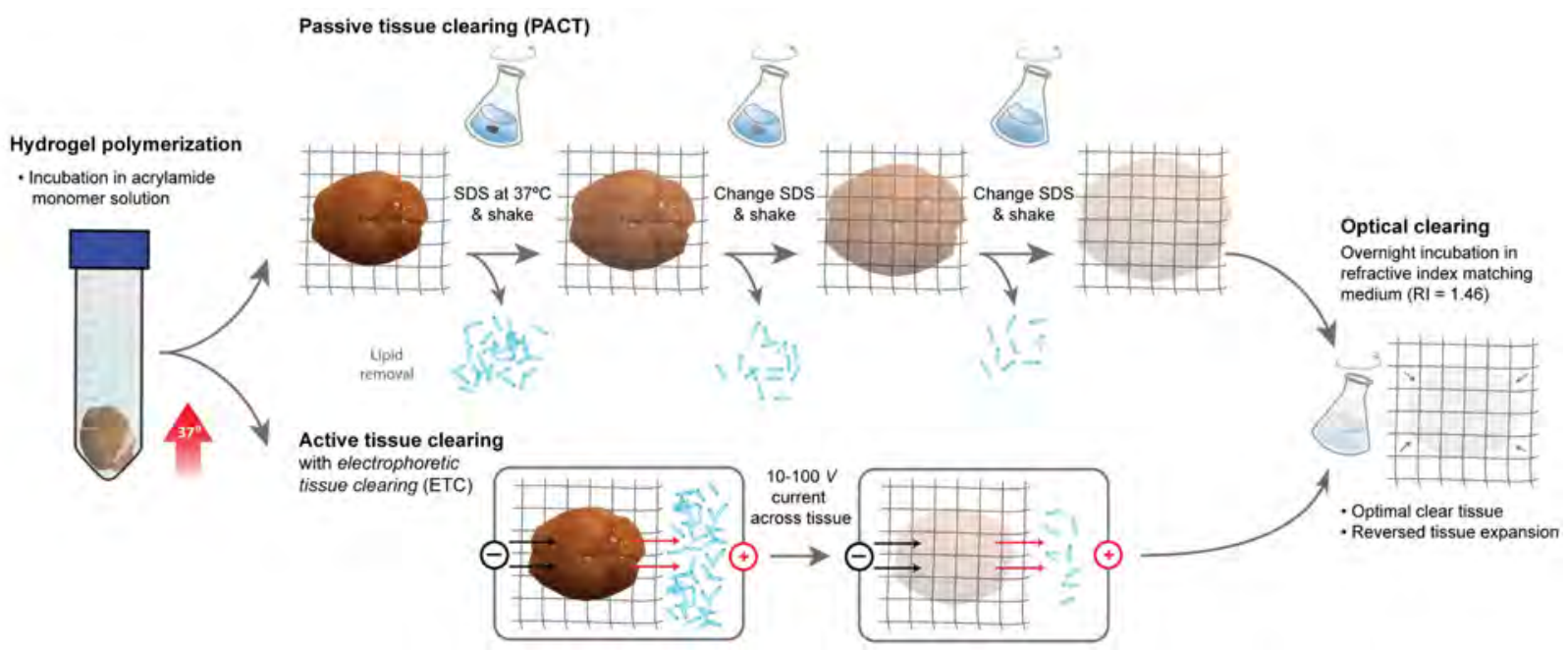

Figure 2: CLARITY tissue clearing: passive and active.

The hydrogel-tissue hybrid is formed (left) by an incubation in the acrylamide monomer solution with the initiator VA-044. Polymerization is activated by heat. Afterwards, the lipids can either be cleared from the tissue by passive (top) or active (bottom) methods. The detergent, SDS, collects lipids and carries them out of the tissue leaving behind a transparent hydrogel-tissue hybrid. Passive tissue clearing, PACT (top), is straightforward and inexpensive, but also a slower process as it relies on diffusion, which is enhanced by gentle shaking and an elevation of temperature. During this process the tissue absorbs water and expands in volume up to $\sim 200 \%$, which improves the access of antibodies and thus the staining. The swelling is reversed in the hygroscopic medium (right). The alternative method of tissue clearing requires more equipment and supervision as it uses electrophoresis (bottom). The negatively charged lipid micelles are actively carried by the electrical field, which greatly enhance the extraction rate. In the final step of optically clearing the tissue (right) the hydrogel is incubated overnight in a refractive index matching medium to complete transparency.

proteins. For instance, passively clearing of $1 \mathrm{~mm}$ cortical sections takes $\sim 48$ hours at $37^{\circ} \mathrm{C}$ compared to $\sim 12$ hours at $57^{\circ} \mathrm{C}$ (Yu et al., 2017). Yu et al. (2017) found that an elevated temperature range of 42$47^{\circ} \mathrm{C}$ for PACT resulted in faster transparency and deeper imaging depth than $37^{\circ} \mathrm{C}$ without affecting the fluorescence signal. There is reportedly no significant difference in protein loss at higher temperatures such as $55^{\circ} \mathrm{C}$ compared to $37^{\circ} \mathrm{C}$ (Epp et al., 2015).

Passive clearing can be improved by gentle shaking, continuously replacing the clearing solution (figure 2) or with a flow-assisted clearing setup with a circulator. An alternative setup without a circulator is using a $50 \mathrm{ml}$ conical tube perforated with several holes at the $15-20 \mathrm{ml}$ mark and at the bottom of the tube, which is inserted into a $250 \mathrm{ml}$ glass bottle filled with clearing solution. Unidirectional flow is created by using a magnetic stir bar on a stirring hot plate to accelerate the clearing at the desired temperature (capture-clarity.org/optimized-clarity). The clearing time of various tissues and protocols are listed in table 2.

\section{Active lipid removal by electrophoresis}

Tissue is composed of different types of lipids primarily fatty acids and phospholipids. The detergent, SDS, captures the lipids in SDS micelles. The micelles are negatively charged at basic $\mathrm{pH}(7.5-8.5)$ and carries the lipids along the electric field. This electrophoretic tissue-clearing (ETC) enhances the speed of extraction by orders of magnitude such that a large tissue sample e.g. a mouse brain becomes transparent a matter of hours to days instead of days to weeks during passive clearing (Tomer et al., 2014). Lipid clearing using ETC is faster and therefore results in less tissue swelling compared with passive clearing. 
The ECT system should have three elements: 1) The chamber containing the sample and electrodes. 2) A circulator, which controls flow rate and temperature. This can be a simple pump and a liquid reservoir that serves to remove electrophoretic by-products such as acid, bubbles and heat. 3) A buffer filter to filter out larger particles in the clearing solution.

There are, however, important caveats to consider when using ETC. If the electrical field is too strong, small bubbles will form inside the hydrogel and make the hydrogel opaque, while bigger bubbles may rupture hydrogel (Kim et al., 2015). Keeping the voltage small enough to avoid this issue, ETC is a helpful step in clearing the sample. The electric field is recommended to be applied as a low-voltage constant current generator of $250-280 \mathrm{~mA}$ to ensure low voltage field $(10-40 \mathrm{~V})$. Such a field will avoid electrolysis of water in the liquid and formation of bubbles (Lee et al., 2014). Running ETC at higher temperatures $\left(55^{\circ} \mathrm{C}\right.$ ) produces very clear tissue, but the tissue tends to lose structural integrity (Epp et al., 2015). Lowering the temperature $\sim 15^{\circ} \mathrm{C}$ to counteract Joule-heating is also recommended (Kim et al., 2015). Practically the tissue sample is placed in a custom-designed electrophoretic chamber with platinum electrodes as well as drainage and access of liquid (Tomer et al., 2014; Lee et al., 2016). The original CLARITY chamber had wire electrodes with a surface area of $314 \mathrm{~mm}^{2}$, which could clear a mouse brain in 5-16 days, whereas electrode plates with a greater surface area of $1200 \mathrm{~mm}^{2}$ as in ACT gives faster clearing (whole mouse brain and other organs within $24 \mathrm{hrs}$, table 2) and less tissue damage (Lee et al., 2016).

Another caveat of ECT is the flux of lipids is in one direction along the field, which means that the central parts, as well as the parts along borders in parallel with the field, will not have extraction lipids in the same degree as the perpendicular parts. As a result, there is a non-even lipid-extraction and penetration of antibodies when using ECT for ICH. A solution to this problem is, rather than using a static field, to change the direction of the electric field over time, e.g. by rotating the direction. Such rotational electrical field enhances the stochastic electro-diffusion, which enhances lipid extraction as well as staining of large and dense tissue with nuclei dyes, proteins, antibodies (Kim et al., 2015). The two-chamber design with the rotational electrical field can clear mice brains and other organs within 3 days (table 2).

While most chamber designs are freely and commercially available, setting up ETC can be expensive. 3Dprinting of shared designs may significantly reduces costs for experimenters and allow for organ-specific designs (Sulkin et al., 2013; Miller and Rothstein, 2017); e.g. a tissue cutting matrix (Tyson et al., 2015) and imaging chambers (idisco.info/idisco-protocol). An overview of the three ECT approaches and where to find free designs and commercial ETC chambers are summarised (table 1).

Table 1: Active lipid removal using electrophoretic tissue clearing (ETC): protocols and chambers.

\begin{tabular}{|c|c|c|c|c|c|}
\hline Protocol & $\begin{array}{l}\text { Electrodes } \\
\text { and field }\end{array}$ & $\begin{array}{l}\text { Speed and } \\
\text { tissue damage }\end{array}$ & $\begin{array}{l}\text { Time to clear } \\
\text { a mouse brain }\end{array}$ & $\begin{array}{l}\text { Freely available protocol } \\
\text { and chamber blueprints }\end{array}$ & $\begin{array}{l}\text { Commercial } \\
\text { options }\end{array}$ \\
\hline CLARITY & $\begin{array}{l}\text { Wire-electrodes; } \\
\text { unidirectional field } \\
(10-30 \mathrm{~V} ; 280 \mathrm{~mA})\end{array}$ & $\begin{array}{l}\text { (+) Linear with } V \\
\text { Discolouration and } \\
\text { tissue damage }\end{array}$ & 15-16 days & $\begin{array}{l}\text { Chung et al. (2013); Tomer et al. (2014) } \\
\text { Bastrup and Larsen (2017) } \\
\text { wiki.claritytechniques.org }\end{array}$ & \\
\hline$A C T$ & $\begin{array}{l}\text { Large sufrace plate-electrodes; } \\
\text { unidirectional field }(1.5 \mathrm{~A})\end{array}$ & $\begin{array}{l}(+++) \text { Linear with } V \\
\text { Less tissue damage }\end{array}$ & 6 hours & Lee et al. (2016) & $\begin{array}{l}\text { X-CLARITY } \\
\text { (Logos Biosystems) }\end{array}$ \\
\hline $\begin{array}{l}\text { Stochastic } \\
\text { Electrotransport* }\end{array}$ & $\begin{array}{l}\text { Wire-electrodes; } \\
\text { rotating field }(10-100 \mathrm{~V})\end{array}$ & $\begin{array}{l}\text { (++) Quadratic with } V \\
\text { Least tissue damage }\end{array}$ & 3 days & $\begin{array}{l}\text { Sylwestrak et al. (2016) and } \\
\text { www. chunglabresources. com }\end{array}$ & $\begin{array}{l}\text { SmartClear I \& II } \\
\text { (LifeCanvas Tech) }\end{array}$ \\
\hline
\end{tabular}

\section{Loss of fluorescent proteins and antigens}

Many investigations employ viral tracers to induce fluorescent protein expression in specific neuronal populations (figure 3a). However, the fluorescent proteins are vulnerable to over-fixation, denaturation and elution with subsequent signal loss and the fluorescence may require amplification. Another common tool is to image fluorescent reporters such as green- or yellow fluorescent proteins (GFP or YFP), which are expressed exclusively in a specific neuronal population e.g. dopaminergic neurons or parva-albuminergic neurons in transgenic animals (figure $3 \mathrm{~b}$ ). In $1 \mathrm{~mm}$ brain slices with genetically expressed GFP, when cleared by passive CLARITY, tissue transparency reaches a plateau after 5 days, while the fraction of GFP 
bioRxiv preprint doi: https://doi.org/10.1101/144378; this version posted July 12,2017 . The copyright holder for this preprint (which was not certified by peer review) is the author/funder, who has granted bioRxiv a license to display the preprint in perpetuity. It is made available under aCC-BY 4.0 International license.

remaining in the tissue decreases rapidly during clearing (Magliaro et al., 2016), demonstrating a trade-off between transparency and protein retention. Antigens and fluorescent proteins are lost during tissue clearing. The optimal clearing is the shortest duration with the best ratio of transparency and protein retention. Magliaro et al. (2016) measured transparency with a regular digital camera and they measured antigen and fluorescent protein loss into the clearing solution with a fluorescent plate reader or a spectrophotometer.

Table 2: Clearing times for organs and tissues using various protocols. Note that the clearing time do not have a single definition across studies, but is an indication the time to reach sufficient transparency. Organs are whole unless otherwise noted.

\begin{tabular}{|c|c|c|c|c|c|}
\hline Animal & Organ & Size & $\begin{array}{l}\text { Clearing } \\
\text { Protocol }\end{array}$ & $\begin{array}{c}\text { Clearing } \\
\text { time (days) }\end{array}$ & Reference \\
\hline \multirow[t]{36}{*}{ Mice } & \multirow[t]{9}{*}{ Brain } & $1 \mathrm{~mm}$ & $\mathrm{ACT}$ & $2 \mathrm{hrs}$ & Lee et al. (2016) \\
\hline & & $1 \mathrm{~mm}$ & PACT $(4 \% \mathrm{~A}, 0.05 \% \mathrm{~B})$ & 4 & Jensen and Berg (2016) \\
\hline & & $2 \mathrm{~mm}$ & Active CLARITY (2\% PFA, $2 \%$ A) & 2 & Bastrup and Larsen (2017) \\
\hline & & $3 \mathrm{~mm}$ & $\mathrm{ACT}$ & 4 hrs & Lee et al. (2016) \\
\hline & & $3 \mathrm{~mm}$ & Active CLARITY & 3 & Lee et al. (2014) \\
\hline & & whole & $\mathrm{ACT}$ & $6 \mathrm{hrs}$ & Lee et al. (2014) \\
\hline & & whole & Stocastic Electrotransport & 3 & Kim et al. (2015) \\
\hline & & whole & Active CLARITY $\left(4 \mathrm{~d}\right.$ at $37^{\circ} \mathrm{C}, 1 \mathrm{~d}$ at $\left.55^{\circ} \mathrm{C}\right)$ & 5 & Epp et al. (2015) \\
\hline & & whole & Active CLARITY & $12-16$ & Lee et al. (2014) \\
\hline & \multirow[t]{2}{*}{ Brain \& spinal cord } & whole & mPACT & 14 & Woo et al. (2016) \\
\hline & & whole & PACT & 23 & Woo et al. (2016) \\
\hline & Bone & & Bone CLARITY & 21 & Greenbaum et al. (2017) \\
\hline & \multirow{3}{*}{$\begin{array}{l}\text { Embryos } \\
\text { Heart }\end{array}$} & & mPACT & 3 & Woo et al. (2016) \\
\hline & & & mPACT & 15 & Woo et al. (2016) \\
\hline & & & Stocastic Electrotransport & 3 & Kim et al. (2015) \\
\hline & \multirow[t]{7}{*}{ Intestine } & & $\mathrm{ACT}$ & 3 hrs & Lee et al. (2014) \\
\hline & & & Active CLARITY & $8-12$ & Lee et al. (2014) \\
\hline & & & Passive CLARITY & $12-14$ & Neckel et al. (2016) \\
\hline & & & PACT & $12-14$ & Neckel et al. (2016) \\
\hline & & & mPACT & 15 & Woo et al. (2016) \\
\hline & & & PACT & 21 & Woo et al. (2016) \\
\hline & & & Stocastic Electrotransport & 1 & Kim et al. (2015) \\
\hline & \multirow[t]{3}{*}{ Kidney } & & $\mathrm{ACT}$ & 1 & Lee et al. $(2016)$ \\
\hline & & & Active CLARITY & $8-12$ & Lee et al. (2014) \\
\hline & & & Stocastic Electrotransport & 3 & Kim et al. (2015) \\
\hline & \multirow[t]{3}{*}{ Liver } & & ACT & 1 & Lee et al. (2016) \\
\hline & & & Active CLARITY & $18-22$ & Lee et al. (2014) \\
\hline & & & PACT & 22 & Woo et al. (2016) \\
\hline & \multirow[t]{5}{*}{ Lung } & & $\mathrm{ACT}$ & $5 \mathrm{hrs}$ & Lee et al. (2016) \\
\hline & & & Active CLARITY & $13-17$ & Lee et al. (2014) \\
\hline & & & mPACT & 14 & Woo et al. (2016) \\
\hline & & & PACT & 18 & Woo et al. (2016) \\
\hline & & & Stocastic Electrotransport & 3 & Kim et al. (2015) \\
\hline & \multirow[t]{3}{*}{ Pancreas } & & Active CLARITY & $8-12$ & Lee et al. (2014) \\
\hline & & & mPACT & 17 & Woo et al. (2016) \\
\hline & & & PACT & 17 & Woo et al. (2016) \\
\hline \multirow[t]{13}{*}{ Rat } & \multirow[t]{4}{*}{ Brain } & hemisphere & $\mathrm{ACT}$ & 8 hrs & Lee et al. $(2016)$ \\
\hline & & $4 \mathrm{~mm}$ & mPACT & 5 & Woo et al. (2016) \\
\hline & & $4 \mathrm{~mm}$ & psPACT & 7 & Woo et al. (2016) \\
\hline & & $4 \mathrm{~mm}$ & $\mathrm{PACT}$ & 10 & Woo et al. (2016) \\
\hline & Spinal cord section & $4 \mathrm{~mm}$ & PACT $(4 \% \mathrm{~A}, 0.05 \% \mathrm{~B})$ & 6 & Jensen and Berg (2016) \\
\hline & Brain \& spinal cord & whole & mPACT or PARS-mPACT & 21 & Woo et al. (2016) \\
\hline & Heart & & PARS-mPACT & 16 & Woo et al. (2016) \\
\hline & \multirow[t]{2}{*}{ Kidney } & & mPACT or PARS-mPACT & 23 & Woo et al. (2016) \\
\hline & & & PARS-PACT & 23 & Woo et al. (2016) \\
\hline & Liver & & PARS-mPACT & 23 & Woo et al. (2016) \\
\hline & Lung & & PARS-mPACT & 18 & Woo et al. (2016) \\
\hline & Pancreas & & mPACT or PARS-mPACT & 15 & Woo et al. (2016) \\
\hline & Spleen & & mPACT or PARS-mPACT & 19 & Woo et al. (2016) \\
\hline \multirow[t]{3}{*}{ Zebrafish } & \multirow[t]{3}{*}{ Whole adult fish } & & $\mathrm{ACT}$ & 6 hrs & Lee et al. (2016) \\
\hline & & & PACT ( $1 \%$ A, $0.05 \%$ B) & 5 & Cronan et al. (2015) \\
\hline & & & $\mathrm{PACT}(4 \% \mathrm{~A}, 0.05 \% \mathrm{~B})$ & $30+$ & Cronan et al. (2015) \\
\hline
\end{tabular}

\footnotetext{
*A: acrylamide, B: bis-acrylamide
} 

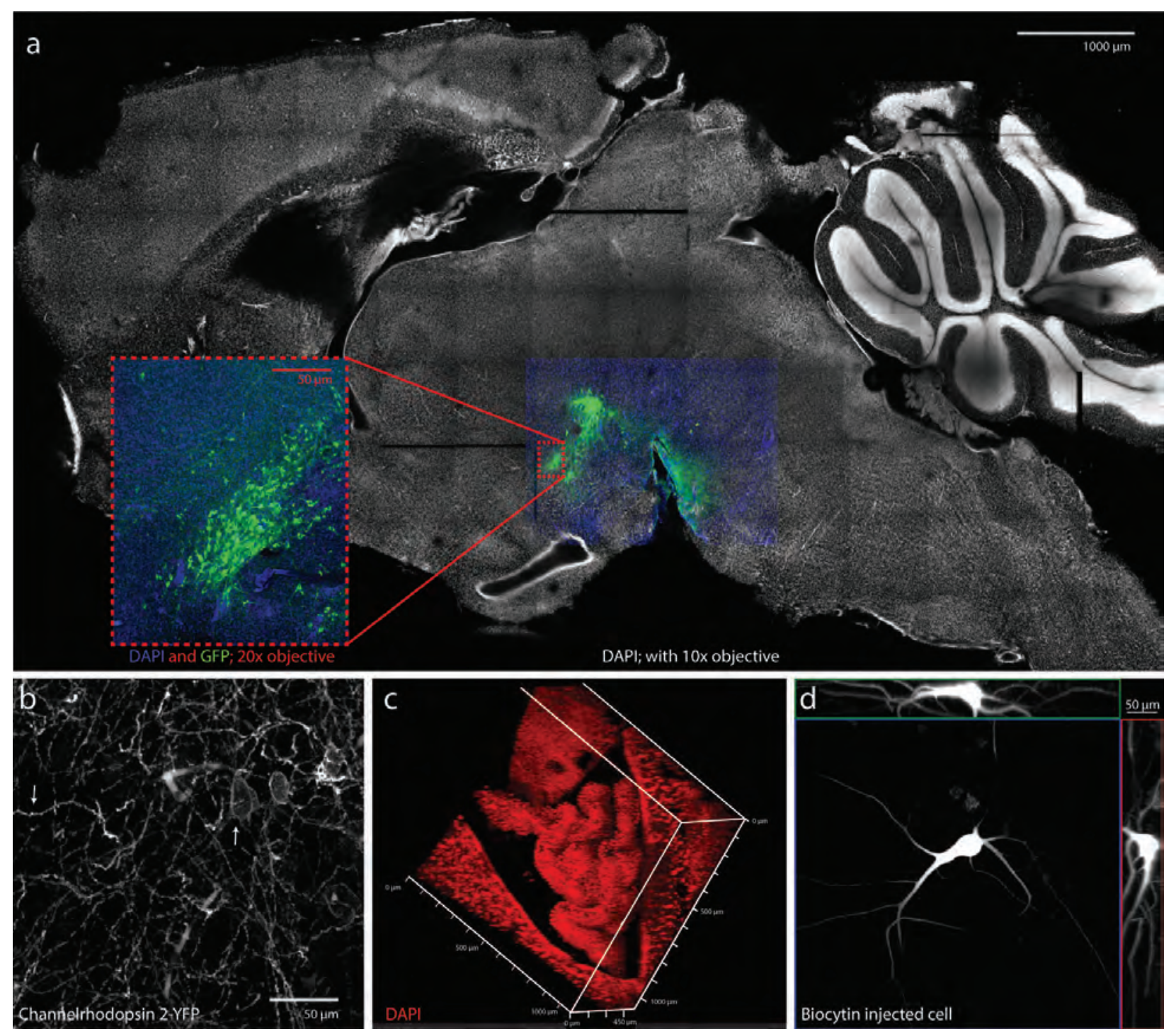

Figure 3: Applications of CLARITY. CLARITY can be used in various purposes. a) Whole field imaging combined with deep tissue imaging (inset) using low magnification $(10 \times)$ air objects and image stitching. Cell nuclei stained (DAPI: white/blue) of a mid-sagittal mouse brain slice (thickness $2 \mathrm{~mm}$ ). Low resolution imaging was used to achieve an quick overview of a slab of CLARITY tissue $(\sim 1 \mathrm{~min})$. Viral injected neurons expressing ChR2-YFP in ventral tegmental area was visualised (green). YFP amplified by IHC with a YFP targeting GFP conjugated antibody) (Navntoft, 2015). b) Endogenous expression of yellow fluorescent protein conjugated with channel-rhodopsin-2 (ChR2-YFP) in PV-cells of a CLARITY-treated cortical slice from a transgenic mouse are visible without need of IHC. The neurites (downward arrow) and membranes of the soma (upward arrow). Objective: standard $20 \times$ air. Depth $\sim 300 \mu \mathrm{m}$ at the maximum of the working distance of $0.55 \mathrm{~mm}$ in the $1 \mathrm{~mm}$ thick slice. c) The lateral ventricle choroid plexus of mouse reconstructed in 3D after CLARITY and DAPI staining. d) Single neuron staining with biocytin following electrophysiology. Biocytin was injected intracellularly during recording from a motoneuron of the adult turtle spinal cord (Petersen et al., 2014). The neuron was located in a $300 \mu \mathrm{m}$ slice and 3D-reconstructed with a maximum intensity projection of $Z$ (blue), $X$ (red) and $Y$ (green) plans of the 65 confocal images $(Z=66$ $\mu \mathrm{m})$ to reveal the morphology of the soma and dendrites. a-d) Tissues were PACT-cleared and imaged in RIMS using a confocal microscope (Zeiss, LSM 700 or 710 ) with standard $10 \times$ or $20 \times$ air objectives (Jensen and Berg, 2016). 


\section{Staining}

The main feature of CLARITY is the ability to combine large volume tissue clearing with molecular phenotyping by IHC and other staining methods. Multiple rounds of staining are possible without damage to the preserved structure since the innate biomolecules are chemically bound in the tissue-hydrogel. The tissue clearing solution containing detergent (SDS) can be used to denature antibodies, disrupt binding, and wash antibodies and other molecular labels out of the hydrogel-embedded tissue as preparation for addition rounds of staining. The procedure is simply: incubate overnight with shaking in PBST at $20-40^{\circ} \mathrm{C}$, then incubate overnight with shaking in clearing solution at $60^{\circ} \mathrm{C}$ to wash out antibodies, finally incubate overnight with shaking in PBST at $20-40^{\circ} \mathrm{C}$ to wash out SDS before next round of IHC and imaging (Tomer et al., 2014). However, there were several shortcomings in this protocol e.g. slow staining, incompatible with lipid dyes and poor retention of RNA, which have since been improved.

\section{Passive versus active staining}

Similar to the clearing of lipids, the application of antibodies for IHC can be performed either passively by diffusion or actively with the assistance of an electrical field or other means. Two of the main challenges in staining are proper uniformity and depth and the penetration of antibodies is relying on diffusion. The slow rate of penetration within the hydrogel is a time-limiting factor in processing samples and thick tissues require weeks to months to adequately label. Increasing the pore size of the hydrogel can be accomplished by reducing acrylamide concentration, but this has limited effect on diffusion speed. The speed is dependent on the molecular weight of the dye or antibody. When choosing a small dye, e.g. DAPI (0.28 kDa), a thick CLARITY-treated tissue can be stained reliably overnight (figure 3a-c), (Jensen and Berg, 2016), whereas staining with heavier antibodies $(150 \mathrm{kDa})$ can take days to weeks. The time of penetration using diffusion can be reduced by half by using smaller antibody fragments such as F(ab') $)_{2}(110 \mathrm{kDa})$ and Fab (50kDa)) (Li et al., 2015). Another approach to improve antibody staining is using high antibody concentrations or two primary antibodies for a single target, which improved staining speed and quality of parvalbumin-expressing neurons (Bastrup and Larsen, 2017).

The PARS method to clear the tissue can also be used as an active staining method where the staining solution is delivered via the vasculature route mimicking blood flow to reach the whole body and all areas of the tissues to increase speed and penetration depth. If only staining of the brain or CNS is desired delivery by a subdural cannulation directly above the olfactory bulb or in the cisterna magna is more effective.

An initial report demonstrated how an electrophoretically-driven approach could decrease the delivery time of antibodies by taking advantage of their net charge. A static and unidirectional $25 \mathrm{~V}$ electric field increased antibody penetration by more than 800-fold compared to simple diffusion (Li et al., 2015). Nevertheless, Kim et al. (2015) found that static electrophoresis resulted in substantial tissue damage, similar to the problems with ETC when clearing lipids (see above). An alternative strategy was proposed by the Chung group, which is based on stochastic electrotransport. The method briefly appeared under the name eTANGO (Richardson and Lichtman, 2015; Hubbert et al., 2014). A rotational electric field selectively dispersed charged molecules without interfering with the endogenous biomolecules. Fluorescent dyes, proteins, and antibodies of different sizes (70-2,000 kDa) was tested using stochastic transport and all gave rapid homogeneous staining of whole brains within a day (Kim et al., 2015).

The benefit of the stochastic electrical field is the more rapid penetration, since speed scales quadratically with the current, and therefore requires a smaller current for the same speed. Hence, the tissue damage is likely to be smaller than for static fields. A static electrical field also has rapid penetration, where the speed scales linearly with the current, but this requires a slightly stronger field for same speed and is therefore more likely to cause damage to the tissue. The main challenge in stochastic electrotransport is building the chamber and buffer flow system. The design is available (www.chunglabresources.com) and a commercial option is expected soon from LifeCanvas Technologies (www.lifecanvastech.com). Lee et al. (2016) demonstrated a simpler and cheaper method based on applying pressure to increase the speed and depth of dyes and antibodies penetration into the tissue, which they coined PRESTO (Pressure-Related 
Efficient and Stable Transfer of macromolecules into Organs) as a part of the ACT-PRESTO protocol. Centrifugal force (c-PRESTO) or convection flow ( $s$-PRESTO; for syringe) enabled rapid IHC in $100 \mu \mathrm{m}$ thick sections within 2-3 h, which compared to passive diffusion requires 1-2 days. c-PRESTO requires a standard table-top centrifuge, while $s$-PRESTO requires a syringe pump.

\section{RNA studies}

Strands of RNA are fixed by PFA and retained in the hydrogel, but the potential histological value from RNA is so far unexplored in most clearing methods. Single-molecule fluorescence in-situ hybridization (smFISH) of RNA has been demonstrated in thin $(100 \mu \mathrm{m})$ PACT-processed sections (Yang et al., 2014). By adding a polymerisation step, hybridization chain reaction (smHCR), the depth of RNA detection is extended to $500 \mu \mathrm{m}$ (Shah et al., 2016), which can visualise e.g. bacterial infections (DePas et al., 2016). However, a modified protocol, EDC-CLARITY, uses carbodiimide chemistry to crosslink the 5' terminal phosphates to adjacent amines and preserve small RNAs before clearing (Sylwestrak et al., 2016). It uses a less rigid hydrogel (4\% PFA, $1 \%$ Acrylamide and 0.00625\% Bis-acrylamide) and an EDC (1-Ethyl-3-(3dimethylaminopropyl)carbodiimide) fixation step before clearing to retain even microRNA. Depending on the length of the oligonucleotide probe, the probe can be amplified by several strategies i.e. Digoxigenin-labeled locked nucleic acids and tyramide signal amplification that enables measurement of activity-dependent transcriptional signatures, cell-identity markers, and diverse non-coding RNAs in large tissue volumes (Sylwestrak et al., 2016).

\section{Lipid and membrane stains}

Fluorescent dyes, such as the generic DiI, DiD and other carbocyanine dyes, are lipophilic and therefore primarily stain cellular membranes (Lai et al., 2017). They are extensively used for retro- and anterograde neuronal labelling as well as for marking the position of extracellular electrodes after electrophysiology (Petersen and Berg, 2016) as an alternative to electrical lesioning (Berg et al., 2009). CLARITY and other clearing techniques, such Sca/e and CUBIC (Hama et al., 2011; Susaki et al., 2014) essentially work by washing away the lipids with detergent and solvents. As an unintended consequence, the clearing process therefore also washes out lipophilic dyes, since they adhere to the lipids (Chung et al., 2013; Richardson and Lichtman, 2015; Tainaka et al., 2016). Nevertheless, there are CLARITY-compatible lipophilic and membrane dyes, which can circumvent this problem. DiI-analogues, sulfonated DiI-variants (SP-DiI), and DiI with a chloromethyl benzamide modification (CM-DiI) are aldehyde-fixable to proteins and reliable remain fluorescent in PACT treated tissue (Jensen and Berg, 2016). An alternative is to stain the membranes post-mortem or after tissue-clearing, even with fixable (SP-DiI) or regular DiI (Jensen and Berg, 2016; Xavier et al., 2017). Similarly, the smaller lipophilic FM dyes, are used to image synaptic vesicle exocytosis and endocytosis and has an analogous chemical structure to DiI. FM 1-43FX is a modified FM dye with an aldehyde-fixable aliphatic amine terminal, that also reliably remains and fluoresces stable in PACT treated tissue (Jensen and Berg, 2016).

Since the DiI-analogues are covalently bound to primary amines on proteins by methylene bridges following aldehyde fixation, they are not removed during lipid extraction by solvents or detergents. Other membrane probes that have a aldehyde-fixable anchor point such as mCLING (Revelo et al., 2014) are likely also CLARITY-compatible. Despite the lipid removal and disruption of the lipid membranes, it is possible to perform immunocytochemistry on membrane associated proteins e.g. tight junctions proteins (e.g. Zonula Occludens-1) and channels (e.g. Aquaporin-4) (Neckel et al., 2016).

\section{Other dyes}

Intracellular neuronal labelling is often performed using the generic amide dyes neurobiotin or biocytin. The delivery of such dyes into the neuronal cytoplasm is accomplished either by an intracellular electrode after electrophysiological recording (Petersen et al., 2014; Vestergaard and Berg, 2015; Petersen and Berg, 2016) or by uptake from the nearby surroundings left by juxtacellular deposits in association with extracellular 
recordings (Wilson and Sachdev, 2004). The dyes are amides and therefore aldehyde-fixable and compatible with CLARITY. Biocytin is not washed out of the cell during CLARITY and can be stained with streptavidin conjugated dye, e.g. Cyanine-3, akin to regular IHC (figure 3d).

CLARITY can also be combined with classical histology such as hematoxylin-eosin and Heidenhain's azan stain, suggesting potential use in histopathology (Neckel et al., 2016) or combined with colorimetric (nonfluorescent) methods such as horseradish peroxidase conversion of diaminobenzidine to a coloured insoluble product (Sung et al., 2016).

\section{Minimizing autofluorescence}

Two primary sources of autofluorescence in CLARITY treated tissue are heme and lipofuscin. It is therefore important to remove as much blood as possible to reduce the autofluorescent signal from heme. Under normal conditions, blood is removed during the initial cardiac perfusion, but in special situations where perfusion is not possible, such as in human tissue, heme can be eluted by incubating hydrogel-embedded PACT sections in aminoalcohol (CUBIC reagent-1: mixture of $25 \%(\mathrm{w} / \mathrm{v})$ urea, $25 \%(\mathrm{w} / \mathrm{v}) \mathrm{N}, \mathrm{N}, \mathrm{N}^{\prime}, \mathrm{N}^{\prime}-$ tetrakis(2-hydroxypropyl) ethylenediamine and 15\% (w/v) Triton X-100 (Susaki et al., 2014), or 25\% (w/v) $\mathrm{N}, \mathrm{N}, \mathrm{N}^{\prime}, \mathrm{N}^{\prime}$-tetrakis(2-hydroxypropyl) ethylenediamine in PBS alone for $12-24 \mathrm{~h}$ at $37^{\circ} \mathrm{C}$ while shaking before (Treweek et al., 2015) or after clearing (Greenbaum et al., 2017). Lipofuscin autofluorescence is partially countered by the tissue clearing process. However, when the tissue sections are thick, they may be incubated in $0.2 \%-1.0 \%(\mathrm{w} / \mathrm{v})$ Sudan Black B, which is a nonfluorescent lipophilic dye, in 70\% ethanol for 1-3 hours immediately before hydrogel-polymerisation in order to further reduce autofluorescence (Treweek et al., 2015).

\section{Optical Clearing}

The final step before imaging is optical clearing, where the average refractive index (RI) of the hydrogel $(\sim 1.46)$ and the imaging solution are closely matched. Photons from both the excitation light and the emitted fluorescence signal scatter if the RI is not matched when travelling through the sample, which limits the quality and depth of imaging. The RI of each solution can be matched to the optimal RI of the tissue or microscope objective by adjusting the concentration of the main ingredient, e.g. Histodenz. Brain tissue usually has an average RI of 1.46-1.47, whereas e.g. bone has 1.48-1.49. It is possible to image without a mounting solution, but in simple water or PBST e.g. PBST (0.1\% Triton X- 100 in PBS) (Poguzhelskaya et al., 2014). However, the tissue remains swollen, and water and PBST have a lower RI ( 1.33) than of the hydrogel $(\sim 1.46)$ and therefore the tissue sample will appear opaque or cloudy. Imaging in water is part of the ePACT method where the tissue is intentionally expanded for greater resolution. There are several different options of mounting solutions (table 4).

\section{FocusClear: the generic imaging solution}

The original FocusClear (CelExplorer Labs Co.) with the main ingredient diatrizoic acid has an RI of 1.454 similar to the tissue-hydrogel, but is expensive $(\sim 29 \mathrm{USD} / \mathrm{ml})$, and not usable for storage (Tomer et al., 2014). If the sample is not washed properly in PBST, a irreversible white precipitate, which is likely caused by a reaction with remaining SDS, can develop within the embedded tissue after a few days. 
bioRxiv preprint doi: https://doi.org/10.1101/144378; this version posted July 12, 2017. The copyright holder for this preprint (which was not certified by peer review) is the author/funder, who has granted bioRxiv a license to display the preprint in perpetuity. It is made available under aCC-BY 4.0 International license.
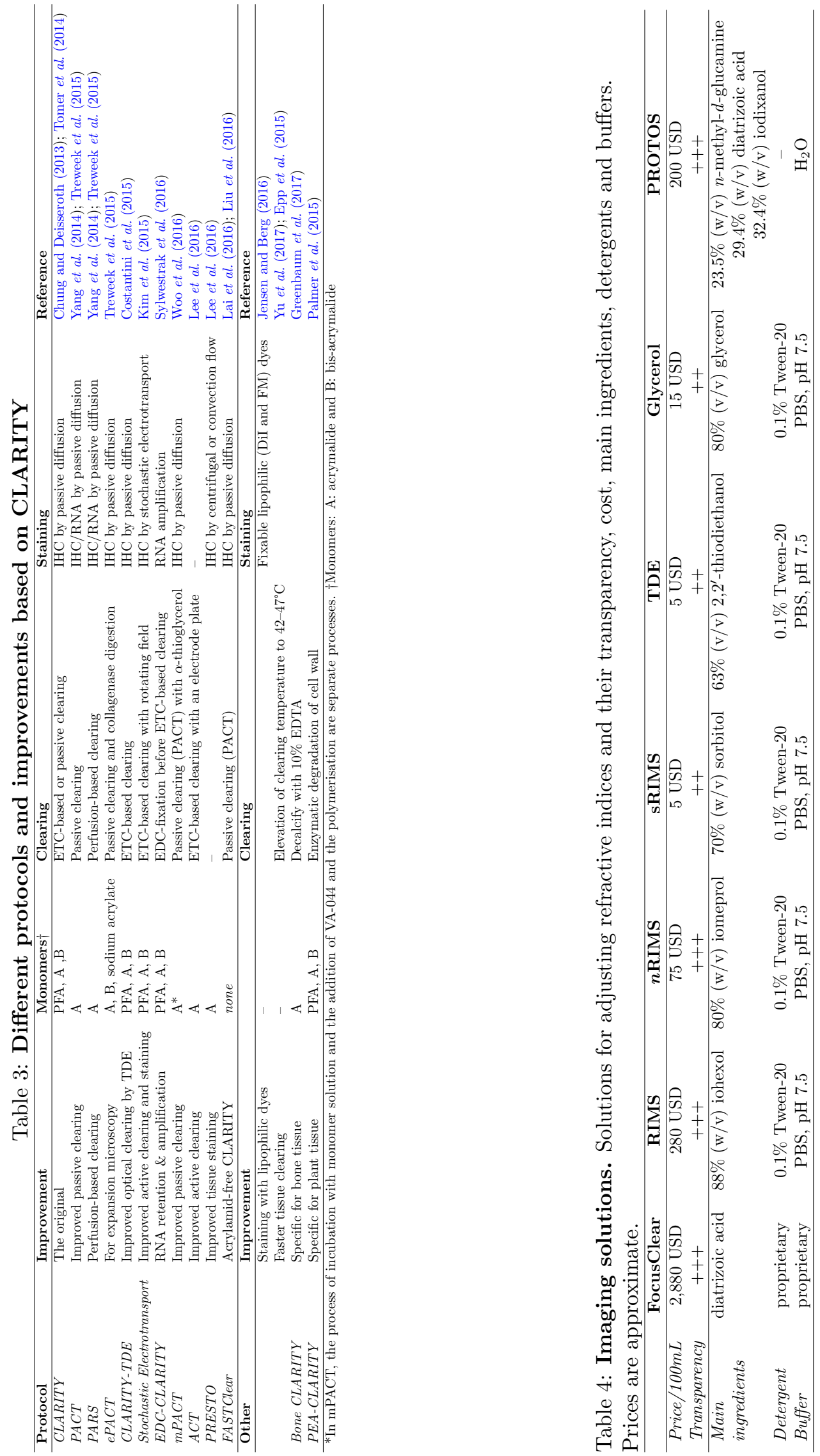


\section{RIMS and $n$ RIMS: the optimal solutions}

Yang et al. (2014) developed an affordable alternative to FocusClear coined refractive index matching solution (RIMS) of $88 \%$ (w/v) Histodenz in PBS with an RI of 1.46. Both Diatrizoic acid and Iohexol (HistoDenz) are complex molecules containing an aromatic ring and three iodine atoms, which provides a large number of electrons for interaction with passing light waves, i.e. high refractive index, but in a relatively low-concentration and low-viscosity solution (Richardson and Lichtman, 2015). Woo et al. (2016) used a $80 \%$ (w/v) solution of Iomeprol-d3 (also known as Nycodenz and Iohexol-d5), referred to as $n$ RIMS, which also has an RI of 1.46. A similar clearing solution is PROTOS (Murray et al., 2015; Kim et al., 2015). RIMS reportedly works better for rodent brains and is reportedly less ideal for human brain tissue, where 47\% TDE in PB is better (Liu et al., 2015).

\section{Glycerol, Sorbitol and TDE: affordable alternatives}

Glycerol, sorbitol, and thiodiglycol (2,2'-thiodiethanol, TDE) are water-soluble and low-viscosity liquids that can be used to tune an aqueous solution over a range of refractive indices by dilution in water. Glycerol and sorbitol are inexpensive and are often found in conventional clearing reagents and in mounting media. TDE was initially used in mounting media for super-resolution microscopy (Staudt et al., 2006), but concentrations of 40-60\% (v/v) can also clear large tissues i.e. rodent brains (Costantini et al., 2015; Aoyagi et al., 2015). Solutions with $63 \%(\mathrm{v} / \mathrm{v})$ TDE, $80 \%(\mathrm{v} / \mathrm{v})$ glycerol, or $70 \%(\mathrm{w} / \mathrm{v})$ sorbitol (coined sRIMS) all have an RI of $\sim 1.46$. One drawback to TDE is that at high concentrations it reduces the brightness of some green fluorophores (Staudt et al., 2006). TDE (47\%) in PB (instead of PBS) is reportedly better for RI-matching in human tissues (Liu et al., 2015). RIMS outperformed sRIMS and glycerol regarding imaging resolution and depth (Yang et al., 2014; Marx, 2014). Another option is a mix of DMSO and D-sorbitol (Economo et al., 2016).

\section{Storage of CLARITY tissue}

All solutions apart from FocusClear can be used for storage. However, a slight loss of fluorescent signal of AlexaFluor-568 has been reported in glycerol (Liu et al., 2015), although the fluorescent signal loss of (red) DiI-dyes has not been observed over 6 months in glycerol (Jensen and Berg, 2016). Storage at room temperature as opposed to using refrigeration is recommended since precipitate can appear at lower temperatures. All solutions should include $0.01 \%$ sodium azide to prevent bacterial and fungal growth. Lowering the PBS concentration to $0.005 \mathrm{M}$ phosphate buffer reduces the appearance of salt precipitate at colder temperatures i.e. $4^{\circ} \mathrm{C}$ (Treweek et al., 2015).

\section{Imaging CLARITY tissue}

Imaging of the clarified tissue is more difficult than conventional histological samples. The point of the lipid removal is to make the tissue transparent for the purpose of imaging in depth. This changes the task from imaging single or several 2-dimensional (2D) sections to a 3-dimensional (3D) volume, which is a much larger volume than what is used in conventional microscopy (figure 3c-d). Such imaging requires considerations of imaging time and resolution when selecting the microscope and objective as well as sample size.

\section{Choice of microscope}

Standard light microscopy is generally not suitable for large transparent tissues samples as the excitation light penetrates the sample and generates fluorescence signal from the whole sample. The signal from the focused plane will be attenuated and likely lost by the fluorescence coming from elsewhere. While it is possible to image highly fluorescent neurons (600 $\mu \mathrm{m}$ deep in $2 \mathrm{~mm}$ tissue) such image will require postprocessing deconvolution (Epp et al., 2015). However, a low magnification (i.e. 1.5-5×) wide field or stereo microscope can be helpful in an initial examination of samples for identifying fluorescence signals from e.g. labelled electrode traces before further investigation (Jensen and Berg, 2016; Petersen and Berg, 2016). 
Imaging of CLARITY-processed tissue samples can be performed using standard confocal microscopes. No modifications are required, but optimal choice of objectives is recommended (see below). However, processing time is slow, especially for high resolution, high sampling, and large volumes, furthermore, illuminates of the entire sample during imaging can lead to photobleaching during long imaging sessions and when imaging at large depths.

The properties of two-photon microscopy lead to significant lower photobleaching of fluorophores and may also provide greater imaging depths than confocal microscopy. The serial point-by-point scanning in 3D tissue is similarly slow.

Light-sheet microscopy is a 3D imaging technique is ideal for clarified samples. Light-sheet microscopy achieves optical sectioning by selectively confining the illumination to the plane of interest by using a Gaussian or a Bessel beam from the side of the tissue. Furthermore, while confocal and two-photon microscopy is point scanning, and hence inherently slow, light-sheet microscopy uses fast sCMOS or CCD camera sensors to image the selectively illuminated focal plane, resulting in minimal photobleaching and increased imaging speeds that are 2-3 orders of magnitude faster than confocal and two-photon microscopy (Tomer et al., 2014).

\section{Microscope objectives}

Objectives with high numerical aperture and long working distances are desirable for maximum imaging depth and resolution. Furthermore, objectives should be optimised for an RI of 1.46 for CLARITY cleared tissues. Several objectives have been developed specifically for CLARITY (table 5).

When using a non-optimized objective, it is best to use the one designed for the RI near 1.46 e.g. glycerine (RI 1.47) or oil immersion (RI 1.52). Water-immersion lenses (RI 1.33) work better than air objectives (RI 1). Furthermore, it is time-consuming imaging a large area using a $25 \times$ objective, since this requires capturing and stitching of multiple tiles of images. Such strategy also increases the risk of photobleaching. A lower magnification 10x can be more useful to image over larger areas (figure 3a), and they have longer working distances. Indeed, the affordable and commonly available low magnification (10-20×) air lenses are compatible and have been successfully used for several CLARITY studies (Jensen and Berg, 2016; Hsiang et al., 2014; Poguzhelskaya et al., 2014; Bastrup and Larsen, 2017). Images in figure 3 were captured with low magnification (10-20×) air lenses. CLARITY-based tissue clearing provided an increased signal-to-noise ratio, and staining homogeneity in super-resolution stimulated emission depletion (STED) microscopy (i.e. with a $100 \times$ objective) of kidney tissue (Unnersjö-Jess et al., 2015). During extended imaging moisture can evaporate from the imaging medium and cause subtle changes RI and resulting in aberrations and loss of resolution. A hygroscopic imaging media or sealed chamber can prevent this.

Table 5: Microscope objectives optimised for imaging CLARITY samples

\begin{tabular}{|c|c|c|c|c|c|}
\hline Model & Manufacturer & $\begin{array}{c}\text { Numerical } \\
\text { Aperture }\end{array}$ & Magn. & $\begin{array}{l}\text { Working } \\
\text { Distance }\end{array}$ & $\begin{array}{l}\text { Refractive } \\
\text { Index }\end{array}$ \\
\hline $\mathrm{XLPLN10} \times$ SVMP & Olympus & 0.6 & $10 \times$ & $8.0 \mathrm{~mm}$ & $1.33-1.52$ \\
\hline LSFM Clearing $20 \times / 1.0$ & Zeiss & 1.0 & $20 \times$ & $5.6 \mathrm{~mm}$ & 1.45 \\
\hline Clr Plan-APOCHROMAT 20×/1.0 Corr & Zeiss & 1.0 & $20 \times$ & $5.6 \mathrm{~mm}$ & 1.45 \\
\hline Clr Plan-NEOFLUAR $20 \times / 1.0$ Corr & Zeiss & 1.0 & $20 \times$ & $5.6 \mathrm{~mm}$ & 1.45 \\
\hline HC FLUOTAR L $25 \times / 1.00$ IMM motCORR VISIR & Leica & 1.0 & $25 \times$ & $6.0 \mathrm{~mm}$ & 1.46 \\
\hline XLSLPN25 $\times$ GMP & Olympus & 1.0 & $25 \times$ & $8.0 \mathrm{~mm}$ & $1.41-1.52$ \\
\hline
\end{tabular}

\section{Stereology and tractography}

Quantification of total cell numbers, densities and projections in tissue while preserving spatial information has been a challenge in stereology, since it relies on interpretation of $2 \mathrm{D}$ sections of tissues and statistical sampling methods from several histological tissue sections (Gundersen and Jensen, 1987; Walloe et al., 2011). 
bioRxiv preprint doi: https://doi.org/10.1101/144378; this version posted July 12,2017 . The copyright holder for this preprint (which was not certified by peer review) is the author/funder, who has granted bioRxiv a license to display the preprint in perpetuity. It is made available under aCC-BY 4.0 International license.

Applying stereological methods to cleared tissues eliminates the need for labour-intensive sectioning. Furthermore, clearing and counting in the whole $3 \mathrm{D}$ volumes rather than multiple sampled 2D sections allows for better stereological estimates. Stereology in CLARITY tissue also has the advantage of the ability to detect subtle changes that might be overlooked because of sampling variance (Erskine and Khundakar, 2016; Greenbaum et al., 2017; Bastrup and Larsen, 2017). However, the computational challenge of aligning images, down-sampling, and creating a 3D-visualisation are currently only semi-automated and for many investigators such task represents a strain. The performance of automated cell detection and segmentation algorithms as alternatives to manual stereological cell counting are still limited by lower detection rates and higher false-positive rates (Schmitz et al., 2014).

Similarly, quantifying axon tracts is also a challenge. Therefore, Deisseroth and colleagues developed a method to compute 3D structure tensors from CLARITY images using tools adapted from diffusion-MRI tractography (Ye et al., 2016). Ye et al. (2016) used activity dependent viral expression of fluorescent proteins to quantify axonal projections of behaviourally defined neuronal populations. They termed this method $C$ LARITY-based $a$ ctivity projection tracking upon recombination (CAPTURE). The method requires viral tools and light sheet imaging, but software for this large-scale image analysis is freely available at captureclarity.org.

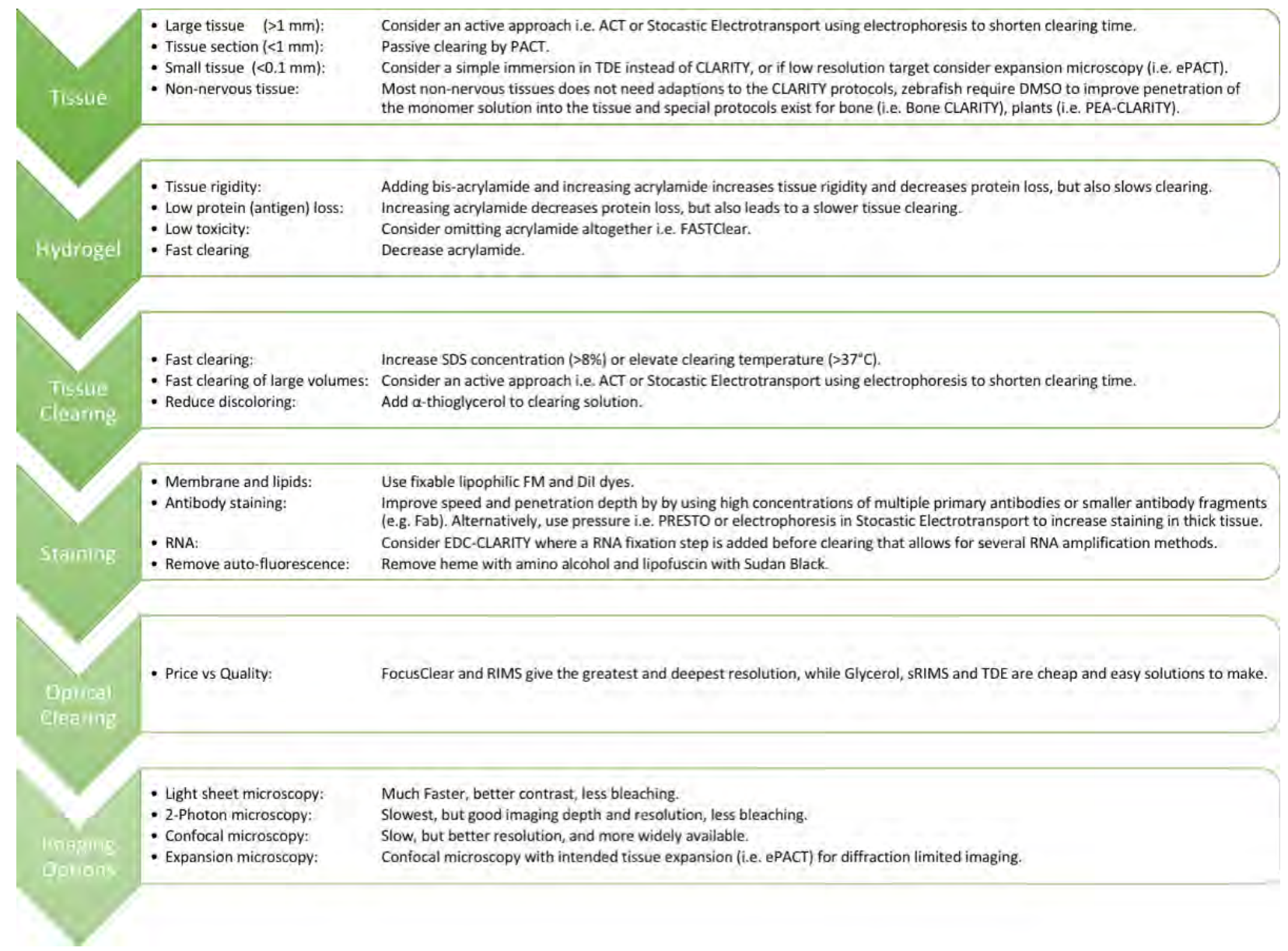

Figure 4: Factors and qualities when selecting and optimising a CLARITY-protocol. 


\section{Author recommendations}

Several qualities are worth considering when selecting or optimising a CLARITY protocol (figure 4). From our experience we recommend the following:

For most tissue use PACT or mPACT: The passive protocols are uncomplicated and inexpensive to setup for novel users. The protocols that omits PFA result in faster clearing with less protein loss and better staining. However, we also recommend including $0.05 \%$ bis-acrylamide in the monomer solution because it makes for a more rigid hydrogel. The solidification of the monomer solution surrounding the tissue is an indicator of successful polymerisation, although bis-acrylamide may slow the clearing. Clearing speed can further be improved by elevating the temperature during clearing to $42-47^{\circ} \mathrm{C}$ and employing mPACT. A minimalist incubation chamber can consist of a styrofoam box with a temperature-controlled heating pad, and then placing the box and a gentle lab shaker.

For large tissues use ETC: For active clearing of large tissues with a simple ETC chamber with single wires for thick tissue sections (1-3 mm), we recommend the design by Bastrup and Larsen (2017) where the distance between wires can easily be adjusted and enables tissue clearing of variable tissue sizes while minimising the resistance and limiting the heat generated in the system. For whole brains or organs, we recommend the more elaborate stochastic electrotransport approach. The addition of $0.5 \% \alpha$-thioglycerol to prevent tissue discolouration during electrophoresis recommended regardless of chamber design.

Use glycerol and RIMS: Selecting an imaging solution is a matter of price versus quality. We regularly use $80 \%$ glycerol and RIMS for imaging and storage. See table 4 for options of mounting solutions.

\section{Successful applications using CLARITY}

CLARITY is applicable not only to nervous tissue, but in principle to any biological tissue. The spinal cord is enveloped by dense grey matter, and the myelin can be difficult, although not impossible, to clear, and limits access to the internal white matter (Jensen and Berg, 2016; Spence et al., 2014; Liang et al., 2015, 2016). One simple solution is to split the spinal cord down the midline into two hemisections, which may be easier to stain and image than using PARS-CSF. While CLARITY was originally demonstrated in mice and rat brains, CLARITY and its variants have been used in several other tissues and organisms. Zebrafish is a popular neuroscience model organism and has been cleared in PACT, but with an added 5\% DMSO to the monomer solution to increase penetration as well as $1 \%$ PFA and $0.05-0.025 \%$ bis-acrylamide to increase rigidity (Cronan et al., 2015; Frétaud et al., 2017).

\section{Human samples}

Application of CLARITY on human brain samples opens the possibility of visualising human pathology in a novel way. Transcardial perfusion is obviously impossible and clinical samples are usually fixed and stored in formalin over extended periods. Indeed, the human pathology of Alzheimer's (Ando et al., 2014), Parkinson's (Liu et al., 2015), neurodegeneration due to mitochondrial disease (Phillips et al., 2016), autism (Chung et al., 2013) as well as intractable epilepsy (Costantini et al., 2015) have been visualised in 3D by CLARITY on formalin-fixed tissues. A frozen brain sample, which was PFA-fixed and cryoprotected in sucrose, has also been cleared and stained using CLARITY (Phillips et al., 2016). The human enteric nervous system was also studied recently using CLARITY (Neckel et al., 2016). The speed of tissue clearing differs between CNS regions depending on the degree of myelination and the duration of formalin fixation. The transient tissue expansion during CLARITY-clearing of animal tissue has been observed to be irreversible in human brain tissues, especially after prolonged (>40 days) passive tissue clearing (Liu et al., 2015). Lai et al. (2016) 
tested an acrylamide-free version of CLARITY, i.e. essentially only washing with SDS followed by RIMS, and found it gave better results for formalin-fixed tissue. They argued that the previously suggested tissue-PFAacrylamide cross-linking does not actually occur. For this reason, omitting acrylamide is better and they named this protocol Free of acrylamide sodium dodecyl sulphate (SDS)-based tissue-clearing (FASTClear) (Liu et al., 2016).

\section{Beyond the CNS}

The enteric nervous system and mesenteric vasculature can be visualised in 3D with CLARITY (Neckel et al., 2016). While it is possible to clear skeletal muscle with CLARITY, labelling the neuromuscular junctions with fluorescently labelled $\alpha$-bungarotoxin has not been possible, likely due to the cross-linking and fixation preventing the access of the toxin to the acetylcholine receptors (Milgroom and Ralston, 2016). However peripheral nerves could be targeted by IHC or an anterograde lipophilic tracer e.g. SP-DiI or a viral tracer instead. It remains to be tested whether labelling of Isolectin B4-positive nociceptor cells is compatible with CLARITY clearing. Neurovasculature has also been studied, where the tissue is incubated in or flushed with antibodies through the vasculature, i.e. anti-CD31 (Neckel et al., 2016; Woo et al., 2016). The endothelial cells could also be stained by flushing the vasculature with a DiI-dye or biocytin before fixation.

\section{Muscle and bone}

It is possible to clear skeletal, cardiac and smooth muscle with CLARITY-based clearing with no modifications to the protocols (Yang et al., 2014; Epp et al., 2015; Milgroom and Ralston, 2016; Gloschat et al., 2016; Kolesová et al., 2016; Sung et al., 2016; Ding et al., 2017). However, the collagen-rich tendons are difficult to make transparent, similar to the myelin-rich white matter of the spinal cord. Extended clearing time and adjustment of the RIMS RI may improve tendon transparency. Chondrocytes can be stained with the fixable lipophilic dye, DiI-SP (Jensen and Berg, 2016; Calve et al., 2015). Bone tissue, however, is challenging since it has low lipid content, a hard mineral component in addition to the soft bone marrow. Clearing osseous tissue can be done using solvent based methods (Richardson and Lichtman, 2015; Greenbaum et al., 2017). Bone tissue can also be cleared using CLARITY by adding a decalcification step, PACT-deCAL, in which tissue is placed in a $0.1 \mathrm{M}$ EDTA (in PBS, $\mathrm{pH} 8$ for 2 days) during PACT-clearing with increased SDS concentration and $\mathrm{pH}(8-10 \%$ SDS and $\mathrm{pH}$ 8). Nevertheless, this gave only modest visualisation depth of 200-300 $\mu \mathrm{m}$ (Treweek et al., 2015). By extending and increasing the decalcification step (0.3 M EDTA and 14 days) Greenbaum et al. (2017) was able to extend visualisation depth to $1.5 \mathrm{~mm}$ in a protocol called 'Bone CLARITY'. The heme-rich bone marrow also presents a problem regarding autofluorescence, which has be reduced by removing heme with amino alcohol before refractive index matching (figure 5). The osteoblasts can be stained with the fixable lipophilic dye CM-DiI (Jensen and Berg, 2016; van Gastel et al., 2012).

\begin{tabular}{|c|c|c|c|c|c|c|c|c|c|c|c|}
\hline PACT & Fixation & & & $\begin{array}{c}\text { Hydrogel } \\
\text { Polymerisation }\end{array}$ & & $\begin{array}{l}\text { Lipid } \\
\text { Removal }\end{array}$ & & Wash & & & $\begin{array}{l}\text { Refactive Index } \\
\text { Matching }\end{array}$ \\
\hline $\begin{array}{l}\text { Trowoek of al. } \\
2016\end{array}$ & $\begin{array}{l}\text { Transcardial } \\
\text { PFA-fixation }\end{array}$ & & & $\begin{array}{l}\text { As in PACT } \\
\text { (A4P0) }\end{array}$ & & $\begin{array}{c}\text { As in PACT } \\
\left.\text { (8\% SDS, pH 7.5, } 37^{\circ} \mathrm{C}\right) \\
4.5 \text { days }\end{array}$ & & $\begin{array}{l}\text { In PBS } \times 3 \\
\text { over } 1 \text { day }\end{array}$ & & & $\begin{array}{l}\text { Incubation in RIMS } \\
\text { RI } 1.47 \text { overnight }\end{array}$ \\
\hline PACT deCAL & Fixation & & & $\begin{array}{c}\text { Hydrogel } \\
\text { Polymerisation }\end{array}$ & $\begin{array}{c}\text { Lipid } \\
\text { Removal }\end{array}$ & Decalcification & $\begin{array}{c}\text { Lipid } \\
\text { Removal }\end{array}$ & Wash & & & $\begin{array}{l}\text { Refactive Index } \\
\text { Matching }\end{array}$ \\
\hline $\begin{array}{l}\text { Trowoek et al. } \\
2016\end{array}$ & $\begin{array}{l}\text { Transcardial } \\
\text { PFA-fixation }\end{array}$ & & & $\begin{array}{l}\text { As in PACT } \\
\text { (A4PO) }\end{array}$ & $\begin{array}{l}\text { 8-10\% SDS, } \\
\text { pH 8, at } 37^{\circ} \mathrm{C} \\
\text { for } 24 \mathrm{hrs}\end{array}$ & $\begin{array}{l}3 \% \text { wiv }(0.1 \mathrm{M}) \\
\text { EDTA in PBS, pH 8, } \\
\text { at } 37^{\circ} \mathrm{C} \text { for } 2 \text { days }\end{array}$ & $\begin{array}{l}\text { 8-10\% SDS, } \\
\text { PH 8. at } 37^{\circ} \mathrm{C} \\
\text { for } 24 \mathrm{hrs}\end{array}$ & $\begin{array}{l}\text { In PBS } \times 3 \\
\text { over } 1 \text { day }\end{array}$ & & & $\begin{array}{l}\text { Incubation in RIMS } \\
\text { RI 1.48-1.49 } \\
\text { overnight }\end{array}$ \\
\hline Bone CLARITY & Fixation & Post-fixation & Decalicification & $\begin{array}{c}\text { Hydrogel } \\
\text { Polymerisation }\end{array}$ & & $\begin{array}{c}\text { Lipid } \\
\text { Removal }\end{array}$ & & Wash & $\begin{array}{l}\text { Heme auto- } \\
\text { fluorescence removal }\end{array}$ & Wash & $\begin{array}{l}\text { Refactive Index } \\
\text { Matching }\end{array}$ \\
\hline $\begin{array}{l}\text { Greenbaum ef at. } \\
2017\end{array}$ & $\begin{array}{l}\text { Transcardial } \\
\text { PFA-fixation }\end{array}$ & $\begin{array}{l}\text { Extracted tissue } \\
\text { post fixed } \\
\text { overnight } \\
\text { in PFA }\end{array}$ & $\begin{array}{l}10 \% \text { w/V }(0.34 \mathrm{M}) \text { EDTA in } \\
\text { PBS, pH } 8 \text {, with ssiring at }{ }^{4} \mathrm{C} \\
\text { and daily butfer exchange } \\
\text { for } 2 \text { woeks }\end{array}$ & $\begin{array}{l}\text { As in PACT } \\
\text { (A4P0) }\end{array}$ & & $\begin{array}{l}\text { As in PACT } \\
8 \% \text { SOS, pH 7.5, at } 37^{\circ} \mathrm{C} \\
4.5 \text { days }\end{array}$ & & $\begin{array}{l}\text { In PBS } \times 3 \\
\text { over } 2 \text { days }\end{array}$ & $\begin{array}{l}\text { 25\% wiv amino alcoohol } \\
\text { in PBS, pH 9, at } 37 \mathrm{C} \\
\text { with stiring }\end{array}$ & $\begin{array}{l}\text { In PBS } \times 3 \\
\text { over } 2 \text { days }\end{array}$ & $\begin{array}{l}\text { Stepwise incubation } \\
\text { over } 3 \text { days in RIMS } \\
\text { RI 1.38, 1.43, 1.47 }\end{array}$ \\
\hline
\end{tabular}

Figure 5: Bone tissue clearing by modified CLARITY protocols. The steps of the three basic protocols for clearing bone tissue are listed in horizontal direction. The essential modification of the original PACT (top) is the addition of a decalcification step (blue) in PACT deCAL (middle) and Bone CLARITY (bottom). The latter also includes reduction of autofluorescence. 


\section{Other organs and species}

CLARITY-based protocols have been used with little, e.g. lower acrylamide concentrations, or no modifications to clear most other organs such as lever (Lee et al., 2014; Font-Burgada et al., 2015), kidney (Yang et al., 2014; Lee et al., 2014; Unnersjö-Jess et al., 2015), pancreas (Lee et al., 2014; Muzumdar et al., 2016), adrenal gland (Epp et al., 2015), spleen (Epp et al., 2015; Kieffer et al., 2017), lymphoid tissues (Kieffer et al., 2017), intestine (Yang et al., 2014; Lee et al., 2014; Epp et al., 2015; Neckel et al., 2016; Kieffer et al., 2017), testes (Epp et al., 2015; Frétaud et al., 2017), ovaries (Feng et al., 2017), and lung tissue (Yang et al., 2014; Lee et al., 2014; Epp et al., 2015; Saboor et al., 2016). However, given that organs have different densities and ratios of connective tissue, lipids, and protein the clearing times and the average RI of the tissue-hydrogel vary (table 2). For spleen and kidney, the best RI-matching solutions were found to be CUBIC-mount, RIMS, sRIMS and TDE, respectively (Lee et al., 2016).

Vertebrate and invertebrate animal models, such as rabbits, chickens, zebrafish, xenopus, small octopuses were cleared by the ACT (Lee et al., 2016). Other models include sea lamprey (Chung-Davidson et al., 2014) and turtles (figure 3d). Adding an enzymatic degradation step as in Plant-Enzyme-Assisted (PEA)CLARITY, it is possible to remove the plant cell walls after tissue-clearing in SDS to clear and stain whole plant tissues without the need for any sectioning of the material. This can be useful in localisation of protein in intact plant tissue in 3D while retaining cellular structure (Palmer et al., 2015). CLARITY has also been used with hybridization chain reaction to detect rRNA from and visualise bacterial infections (DePas et al., 2016).

\section{Alternative clearing methods}

There are several new and old alternatives to CLARITY with their own advantages and limitations. Tissueclearing methods can be divided into three groups: organic solvent-based, aqueous-based and hydrogel-based (Figure 6).

\section{Organic solvent-based}

The first tissue clearing method by Spalteholz a century ago was based on the replacing water within the tissue with a mixture of organic solvents i.e. benzyl benzoate and methyl salicylate, which improves transparency by reducing light scattering (Spalteholz, 1914). Since benzyl benzoate is insoluble in water, it required an intermediate dehydration step with ethanol. Subsequent organic solvent-based methods have the same scheme i.e. dehydration with lipid solvation followed by an alcohol/ether-step then followed by additional lipid solvation-step and RI-matching (Richardson and Lichtman, 2015). Dodt et al. (2007) refined the method by employing mixture of benzyl alcohol/benzyl benzoate (BABB). However, BABB quenches the emission of fluorescent proteins within hours (Richardson and Lichtman, 2015), and the gentler solvents tetrahydrofuran (THF) and dibenzylether (DBE) in the 3DISCO method prolongs the emission for 1-2 days (Becker et al., 2012; Ertürk et al., 2012). This approach has an advantage in rapid clearing kinetics due to the quick diffusion of small molecules and imaging speed due to a tissue shrinkage. 3DISCO has limited antibody penetration depth $(250 \mu \mathrm{m})$ (Hirashima and Adachi, 2015), but has been improved in the iDISCO protocol (Renier et al., 2017). Organic solvents are generally toxic and some, i.e. THF and DBE, are even explosive.

\section{Aqueous-based}

Aqueous-based clearing solutions work by detergent-based lipid removal and hydration. The RIs are then matched in an aqueous solution of concentrated sugar- or contrast-agents with a high RI (1.44-1.49). The RI-matching is accomplished by the inclusion of glycerol in Sca/eA and Sca/eS (Hama et al., 2011, 2015) or sugars e.g. fructose or sucrose in high concentration in CUBIC, SeeDB, FRUIT (Susaki et al., 2014; 
Ke et al., 2013; Hou et al., 2015). Some protocols use urea to enhance the hydration of biomolecules and improve penetration into the tissue i.e. Sca/e, SeeDB, CUBIC (Hama et al., 2011; Susaki et al., 2014; Ke et al., 2013), although this can lead to tissue swelling. They are better at preserving fluorescent proteins compared with organic solvent-based clearing. Generally, aquous-based clearing induces limited change in tissue size, and the compounds are relatively harmless, but the protocol can be labour intensive.

SeeDB and FRUIT provide good transparency, but they have limited permeability for macromolecules and are therefore incompatible with IHC (Ke and Imai, 2014; Hou et al., 2015). The gentler methods omitting strong detergents, glycerol and amino alcohols (i.e. Sca/eS, SeeDB and FRUIT) are however compatible with lipophilic dyes (Hama et al., 2015; Ke et al., 2013; Hou et al., 2015). Yet, fixable lipophilic dyes are likely compatible with all aqueous- and solvent-based methods (Jensen and Berg, 2016).

\section{Hydrogel-based}

Hydrogel-based clearing is innovative approach, that works similar to aqueous-based methods, but has a more aggressive lipid removal combined with impregnation of the tissue with a monomeric component (Silvestri et al., 2016). Polymers and gels, e.g. paraffin and OCT compound, have long been used to support tissues during sectioning and histology. Hydrogels have been a focus of tissue engineering as a substrate for cell culture and a scaffold for growing organs (El-Sherbiny and Yacoub, 2013). In contrast, in the hydrogel-based clearing, the supporting gel is built from within the tissue by anchoring the cellular components to the gel monomers. Cross-linking produces a polymerization, where the unlinked elements, such as lipids, can be removed and give room for macromolecular probes and IHC (Deisseroth, 2017; Silvestri et al., 2016). Since 2013, many variations and improvements of the original hydrogel-based clearing concept, CLARITY, have emerged, which we reviewed above. However, two divergent approaches are briefly mentioned here.

\section{SWITCH}

Using a system-wide control of interaction time and kinetics of chemicals (SWITCH) Murray et al. (2015) replaced the original polyacrylamide mesh with a more stable dialdehyde, i.e. glutaraldehyde. Glutaraldehyde can penetrate through large tissues at $\mathrm{pH} 3$, circumventing the need for tissue perfusion, and rapidly initiate cross-link reactions deep inside the tissue when the $\mathrm{pH}$ is switched to $\mathrm{pH}$ 7. After fixation, lipids are removed by boiling the tissue at $60-80^{\circ} \mathrm{C}$ in a buffer with SDS. The rigid fixation also preserves some lipids and small molecules such as dopamine after clearing, and the harsh treatment does not result in significant loss of proteins or antigens. A similar on/off control of the binding kinetics of the antibodies improves the penetration antibodies. SWITCH also allows for iterative IHC staining as CLARITY, but it is more stable and allows up to 20 rounds of IHC.

\section{Expansion Microscopy}

This technique transforms small tissue samples or cell cultures into swellable hydrogels similar to that of CLARITY by adding the super-absorbent sodium acrylate copolymer (Chen et al., 2015). The purpose is to study small species without the need for tissue-clearing since the sample is expanded and therefore transparent. The hydrogel serves as a scaffold that is partially enzymatically digested and expanded by almost two orders of magnitude to improve resolution beyond the optical diffraction limit.

\section{Conclusion}

Much work has increased the clearing speed of the method CLARITY and adapted its use to several tissue types i.e. non-nervous tissue, bones, and plants. This increases our understanding of biology in different organs and species. While IHC in large volumes continues to be difficult, the main limitation seems to be in imaging and data processing of the large volumes. Light-sheet microscopy makes image-acquisition fast and easy, but is not readily available to all researchers. Furthermore, large image volumes give large data volumes 


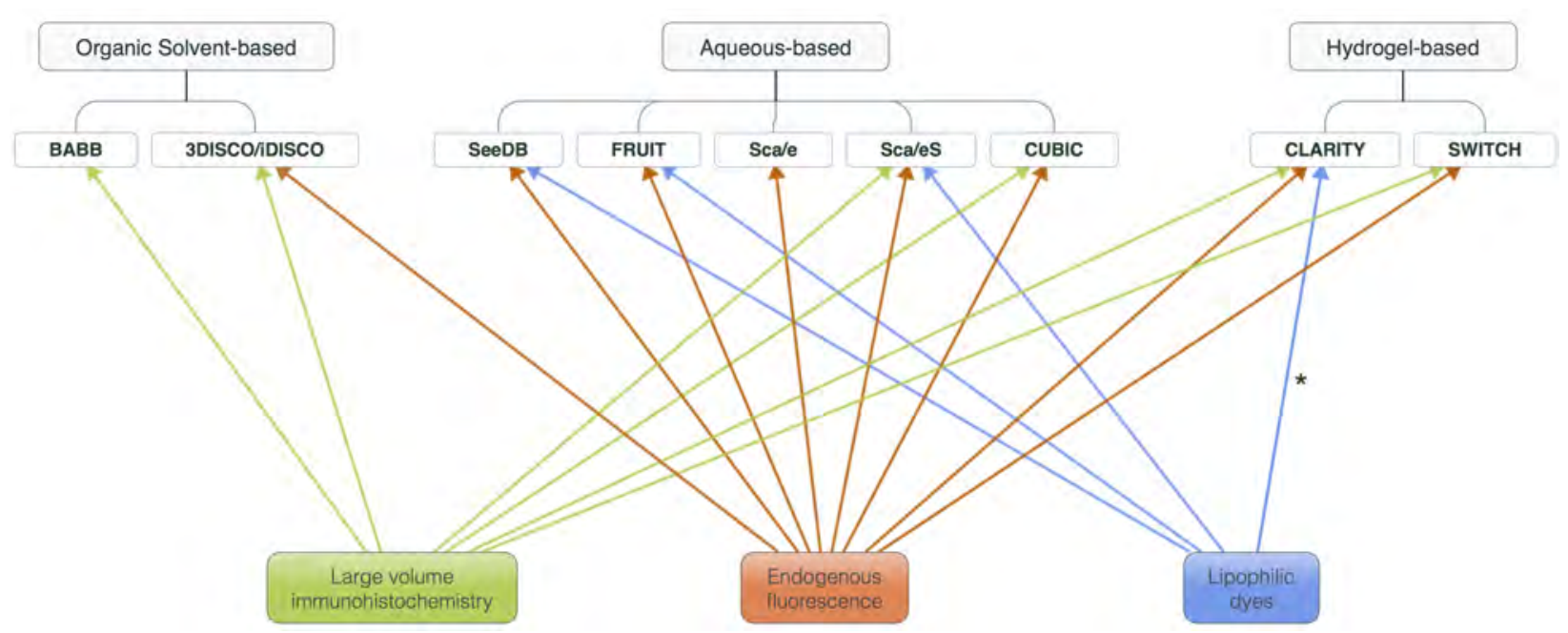

Figure 6: Clearing methods and ideal applications. Clearing methods fall into three categories: organic solvent-based (top, left), aqueous-based (top, middle) and hydrogel-based (top, right). Each method have advantages and shortcomings. The choice of approach should be guided by the histological question. Histological questions are connected with one or more applications listed below: Large volume immunohistochemistry (green), preservation of endogenously expressed fluorescent proteins (red) or tracing using lipophilic dyes (blue). The compatibility of topics with individual methods are indicated by the arrows. For instance, endogenous expression of fluorescent proteins is not ideal to be studied with BABB and 3DISCO, since these methods quenches fluorescence within hours (BABB) or days (3DISCO). * Modified dyes are required since traditional lipophilic dyes are washed out during CLARITY.

(giga- to terabyte) that are difficult to handle and analyse. The challenge of image acquisition and analysis, therefore, lies beyond CLARITY and is a problem shared by all tissue clearing methods. Improvements in large volume image data analysis will improve not only help experimenters using CLARITY, but bring histology into the third dimension.

\section{Acknowledgements}

We thank Editor-in-chief Dr H. Steinbusch for the invitation for this review. Charlotte A. Navntoft for injection of viral tracers, Robertas Guzulaitis for biocytin injection, and Rasmus Christensen and Tania Barkat for providing rodents. Thanks to the Core Facility for Integrated Microscopy, Faculty of Health and Medical Sciences, University of Copenhagen, and the assistance provided by Thomas Braunstein and Laura Plantard. The work is part of the Dynamical Systems Interdisciplinary Network, University of Copenhagen, and supported by the Danish Council for Independent Research medical science (R.W.B).

\section{Conflicts of interest}

None 


\section{References}

Ando, K., Laborde, Q., Lazar, A., Godefroy, D., Youssef, I., Amar, M., Pooler, A., Potier, M., Delatour, B., and Duyckaerts, C. (2014). Inside Alzheimer brain with CLARITY: senile plaques, neurofibrillary tangles and axons in 3-D. Acta Neuropathol, 128, 457-9.

Aoyagi, Y., Kawakami, R., Osanai, H., Hibi, T., and Nemoto, T. (2015). A rapid optical clearing protocol using 2,2'-thiodiethanol for microscopic observation of fixed mouse brain. PLoS One, 10, e0116280.

Bastrup, J. and Larsen, P. H. (2017). Optimized CLARITY technique detects reduced parvalbumin density in a genetic model of schizophrenia. Journal of Neuroscience Methods, 283, 23-32.

Becker, K., Jährling, N., Saghafi, S., Weiler, R., and Dodt, H.-U. (2012). Chemical clearing and dehydration of gfp expressing mouse brains. PLOS ONE, 7(3), 1-6.

Berg, R. W., Chen, M.-T., Huang, H.-C., Hsiao, M.-C., and Cheng, H. (2009). A method for unit recording in the lumbar spinal cord during locomotion of the conscious adult rat. J. Neurosci. Meth., 182(1), 49-54.

Cai, D., Cohen, K. B., Luo, T., Lichtman, J. W., and Sanes, J. R. (2013). Improved tools for the brainbow toolbox. Nat. Methods, 10(6), 540-7.

Calve, S., Ready, A., Huppenbauer, C., Main, R., and Neu, C. P. (2015). Optical clearing in dense connective tissues to visualize cellular connectivity in situ. PLOS ONE, 10(1), 1-14.

Chen, F., Tillberg, P. W., and Boyden, E. S. (2015). Expansion microscopy. Science, 347(6221), 543-548.

Chung, K. and Deisseroth, K. (2013). CLARITY for mapping the nervous system. Nat Methods, 10, 508-13.

Chung, K., Wallace, J., Kim, S., Kalyanasundaram, S., Andalman, A., Davidson, T., Mirzabekov, J., Zalocusky, K., Mattis, J., Denisin, A., Pak, S., Bernstein, H., Ramakrishnan, C., Grosenick, L., Gradinaru, V., and Deisseroth, K. (2013). Structural and molecular interrogation of intact biological systems. Nature, 497, 332-7.

Chung-Davidson, Y.-W., Davidson, P. J., Scott, A. M., Walaszczyk, E. J., Brant, C. O., Buchinger, T., Johnson, N. S., and Li, W. (2014). A new clarification method to visualize biliary degeneration during liver metamorphosis in sea lamprey (petromyzon marinus). (88), e51648.

Costantini, I., Ghobril, J., Di, G. A., Allegra, M. A., Silvestri, L., Müllenbroich, M., Onofri, L., Conti, V., Vanzi, F., Sacconi, L., Guerrini, R., Markram, H., Iannello, G., and Pavone, F. (2015). A versatile clearing agent for multi-modal brain imaging. Scientific Reports, 5, 9808.

Cronan, M. R., Rosenberg, A. F., Oehlers, S. H., Saelens, J. W., Sisk, D. M., Jurcic Smith, K. L., Lee, S., and Tobin, D. M. (2015). Clarity and pact-based imaging of adult zebrafish and mouse for whole-animal analysis of infections. Disease Models \& Mechanisms, 8(12), 1643-1650.

Deisseroth, K. (2017). Optical and chemical discoveries recognized for impact on biology and psychiatry. EMBO reports.

DePas, W. H., Starwalt-Lee, R., Van Sambeek, L., Ravindra Kumar, S., Gradinaru, V., and Newman, D. K. (2016). Exposing the three-dimensional biogeography and metabolic states of pathogens in cystic fibrosis sputum via hydrogel embedding, clearing, and rrna labeling. mBio, $\mathbf{7}(5)$.

Ding, Y., Lee, J., Ma, J., Sung, K., Yokota, T., Singh, N., Dooraghi, M., Abiri, P., Wang, Y., Kulkarni, R. P., Nakano, A., Nguyen, T. P., Fei, P., and Hsiai, T. K. (2017). Light-sheet fluorescence imaging to localize cardiac lineage and protein distribution. 7, 42209.

Dodt, H.-U., Leischner, U., Schierloh, A., Jahrling, N., Mauch, C. P., Deininger, K., Deussing, J. M., Eder, M., Zieglgansberger, W., and Becker, K. (2007). Ultramicroscopy: three-dimensional visualization of neuronal networks in the whole mouse brain. Nat Meth, 4(4), 331-336.

Economo, M. N., Clack, N. G., Lavis, L. D., Gerfen, C. R., Svoboda, K., Myers, E. W., and Chandrashekar, J. (2016). A platform for brain-wide imaging and reconstruction of individual neurons. eLife, 5, e10566.

El-Sherbiny, I. M. and Yacoub, M. H. (2013). Hydrogel scaffolds for tissue engineering: Progress and challenges. Global Cardiology Science and Practice, 2013(3), 38. 
Epp, J. R., Niibori, Y., (Liz) Hsiang, H.-L., Mercaldo, V., Deisseroth, K., Josselyn, S. A., and Frankland, P. W. (2015). Optimization of clarity for clearing whole-brain and other intact organs. eNeuro, 2(3).

Erskine, D. and Khundakar, A. (2016). Stereological approaches to dementia research using human brain tissue. Journal of Chemical Neuroanatomy, 76, Part B, 73 - 81. Unbiased Stereology of Neural Systems: From Normal Aging to Mental Illness and Neurodegenerative Diseases.

Ertürk, A., Becker, K., Jährling, N., Mauch, C. P., Hojer, C. D., Egen, J. G., Hellal, F., Bradke, F., Sheng, M., and Dodt, H.-U. (2012). Three-dimensional imaging of solvent-cleared organs using 3disco. Nat. Protocols, 7(11), 1983-1995.

Feng, Y., Cui, P., Lu, X., Hsueh, B., Möller Billig, F., Zarnescu Yanez, L., Tomer, R., Boerboom, D., Carmeliet, P., Deisseroth, K., and Hsueh, A. J. W. (2017). Clarity reveals dynamics of ovarian follicular architecture and vasculature in three-dimensions. Scientific Reports, 7, 44810.

Font-Burgada, J., Shalapour, S., Ramaswamy, S., Hsueh, B., Rossell, D., Umemura, A., Taniguchi, K., Nakagawa, H., Valasek, M., Ye, L., Kopp, J., Sander, M., Carter, H., Deisseroth, K., Verma, I., and Karin, M. (2015). Hybrid periportal hepatocytes regenerate the injured liver without giving rise to cancer. Cell, 162(4), 766-779.

Frétaud, M., Rivière, L., Job, É. D., Gay, S., Lareyre, J.-J., Joly, J.-S., Affaticati, P., and Thermes, V. (2017). Highresolution 3d imaging of whole organ after clearing: taking a new look at the zebrafish testis. Scientific Reports, 7, 43012 .

Gloschat, C. R., Koppel, A. C., Aras, K. K., Brennan, J. A., Holzem, K. M., and Efimov, I. R. (2016). Arrhythmogenic and metabolic remodelling of failing human heart. The Journal of Physiology, 594(14), 3963-3980.

Greenbaum, A., Chan, K. Y., Dobreva, T., Brown, D., Balani, D. H., Boyce, R., Kronenberg, H. M., McBride, H. J., and Gradinaru, V. (2017). Bone clarity: Clearing, imaging, and computational analysis of osteoprogenitors within intact bone marrow. Science Translational Medicine, $\mathbf{9}(387)$.

Gundersen, H. J. G. and Jensen, E. B. (1987). The efficiency of systematic sampling in stereology and its prediction. Journal of Microscopy, 147(3), 229-263.

Hama, H., Kurokawa, H., Kawano, H., Ando, R., Shimogori, T., Noda, H., Fukami, K., Sakaue-Sawano, A., and Miyawaki, A. (2011). Scale: a chemical approach for fluorescence imaging and reconstruction of transparent mouse brain. Nat Neurosci, 14(11), 1481-1488.

Hama, H., Hioki, H., Namiki, K., Hoshida, T., Kurokawa, H., Ishidate, F., Kaneko, T., Akagi, T., Saito, T., Saido, T., and Miyawaki, A. (2015). ScaleS: an optical clearing palette for biological imaging. Nature neuroscience, 18(10), $1518-1529$

Hirashima, T. and Adachi, T. (2015). Procedures for the quantification of whole-tissue immunofluorescence images obtained at single-cell resolution during murine tubular organ development. PLOS ONE, 10(8), 1-13.

Hou, B., Zhang, D., Zhao, S., Wei, M., Yang, Z., Wang, S., Wang, J., Zhang, X., Liu, B., Fan, L., Li, Y., Qiu, Z., Zhang, C., and Jiang, T. (2015). Scalable and dii-compatible optical clearance of the mammalian brain. Frontiers in Neuroanatomy, $\mathbf{9}, 19$.

Hsiang, H.-L., Epp, J. R., Oever, M. C. v. d., Yan, C., Rashid, A. J., Insel, N., Ye, L., Niibori, Y., Deisseroth, K., Frankland, P. W., and Josselyn, S. A. (2014). Manipulating a "cocaine engram" in mice. The Journal of Neuroscience, 34(42), 14115-14127.

Hubbert, A., Kim, S.-Y., Cho, J. H., Murray, E., Bakh, N., Jo, A., Ohn, K., Ruelas, L., and Chung1, K. (2014). Stochastic electrotransport of activity-modulated molecules for rapid and scalable 3d phenotyping. In 2017 AIChE Annual Meeting, Atlanta, Georgia, USA.

Jensen, K. and Berg, R. (2016). CLARITY-compatible lipophilic dyes for electrode marking and neuronal tracing. Sci Rep, 6, 32674.

Ke, M., Fujimoto, S., and Imai, T. (2013). SeeDB: a simple and morphology-preserving optical clearing agent for neuronal circuit reconstruction. Nat Neurosci, 16, 1154-61.

Ke, M. T. and Imai, T. (2014). Optical clearing of fixed brain samples using SeeDB. Current Protocols in Neuroscience, (January), 1-19. 
Kieffer, C., Ladinsky, M. S., Ninh, A., Galimidi, R. P., and Bjorkman, P. J. (2017). Longitudinal imaging of hiv-1 spread in humanized mice with parallel 3d immunofluorescence and electron tomography. eLife, 6, e23282.

Kim, S.-Y., Cho, J., Murray, E., Bakh, N., Choi, H., Ohn, K., Ruelas, L., Hubbert, A., McCue, M., Vassallo, S. L., Keller, P. J., and Chung, K. (2015). Stochastic electrotransport selectively enhances the transport of highly electromobile molecules. Proceedings of the National Academy of Sciences, 112(46), E6274-E6283.

Kolesová, H., Čapek, M., Radochová, B., Janáček, J., and Sedmera, D. (2016). Comparison of different tissue clearing methods and 3d imaging techniques for visualization of gfp-expressing mouse embryos and embryonic hearts. Histochemistry and Cell Biology, 146(2), 141-152.

Lai, H. M., Liu, A. K. L., Ng, W.-L., DeFelice, J., Lee, W. S., Li, H., Li, W., Ng, H. M., Chang, R. C.-C., Lin, B., Wu, W., and Gentleman, S. M. (2016). Rationalisation and Validation of an Acrylamide-Free Procedure in Three-Dimensional Histological Imaging. PLOS ONE, 11(6), e0158628.

Lai, H. M., Ng, W.-L., Gentleman, S. M., and Wu, W. (2017). Chemical probes for visualizing intact animal and human brain tissue. Cell Chemical Biology, 24(6), 659-672.

Lee, E., Choi, J., Jo, Y., Kim, J. Y., Jang, Y. J., Lee, H. M., Kim, S. Y., Lee, H.-J., Cho, K., Jung, N., Hur, E. M., Jeong, S. J., Moon, C., Choe, Y., Rhyu, I. J., Kim, H., and Sun, W. (2016). Act-presto: Rapid and consistent tissue clearing and labeling method for 3-dimensional (3d) imaging. Scientific Reports, 6, 18631.

Lee, H., Park, J., Seo, I., Park, S., and Kim, S. (2014). Improved application of the electrophoretic tissue clearing technology, CLARITY, to intact solid organs including brain, pancreas, liver, kidney, lung, and intestine. $B M C$ Dev Biol, 14, 48.

Li, J., Czajkowsky, D. M., Li, X., and Shao, Z. (2015). Fast immuno-labeling by electrophoretically driven infiltration for intact tissue imaging. 5, 10640.

Liang, H., Wang, S., Francis, R., Whan, R., Watson, C., and Paxinos, G. (2015). Distribution of raphespinal fibers in the mouse spinal cord. Molecular Pain, 11, s12990-015-0046-x.

Liang, H., Schofield, E., and Paxinos, G. (2016). Imaging serotonergic fibers in the mouse spinal cord using the clarity/cubic technique. (108), e53673.

Liu, A. K., Hurry, M. E., Ng, O. T., DeFelice, J., Lai, H. M., Pearce, R. K., Wong, G. T., Chang, R. C., and Gentleman, S. M. (2015). Bringing clarity to the human brain: visualisation of lewy pathology in three-dimensions. Neuropathology and applied neurobiology.

Liu, A. K. L., Lai, H. M., Chang, R. C., and Gentleman, S. M. (2016). Free-of-acrylamide sds-based tissue clearing (fastclear): A novel protocol of tissue clearing for three-dimensional visualisation of human brain tissues. Neuropathology and Applied Neurobiology.

Magliaro, C., Callara, A. L., Mattei, G., Morcinelli, M., Viaggi, C., Vaglini, F., and Ahluwalia, A. (2016). Clarifying CLARITY: Quantitative Optimization of the Diffusion Based Delipidation Protocol for Genetically Labeled Tissue. Frontiers in Neuroscience, 10.

Marx, V. (2014). Microscopy: seeing through tissue. Nature Methods, 11(12), 1209-1214.

Milgroom, A. and Ralston, E. (2016). Clearing skeletal muscle with clarity for light microscopy imaging. Cell Biology International, 40(4), 478-483.

Miller, S. J. and Rothstein, J. D. (2017). 3d printer generated tissue imolds for cleared tissue using single- and multi-photon microscopy for deep tissue evaluation. Biological Procedures Online, 19(1), 7.

Murray, E., Cho, J. H., Goodwin, D., Ku, T., Swaney, J., Kim, S.-Y., Choi, H., Park, Y.-G., Park, J.-Y., Hubbert, A., McCue, M., Vassallo, S., Bakh, N., Frosch, M. P., Wedeen, V. J., Seung, H. S., and Chung, K. (2015). Simple, scalable proteomic imaging for high-dimensional profiling of intact systems. Cell, 163(6), 1500-1514.

Muzumdar, M. D., Dorans, K. J., Chung, K. M., Robbins, R., Tammela, T., Gocheva, V., Li, C. M.-C., and Jacks, T. (2016). Clonal dynamics following p53 loss of heterozygosity in kras-driven cancers. Nature Communications, 7,12685 . 
Navntoft, C. A. E. (2015). Investigation of Dopamine Signals in Early Parkinson's Disease using Pharmacology and Optogenetics. Master's thesis, University of Copenhagen.

Neckel, P. H., Mattheus, U., Hirt, B., Just, L., and Mack, A. F. (2016). Large-scale tissue clearing (PACT): Technical evaluation and new perspectives in immunofluorescence histology, and ultrastructure. Scientific Reports, 6(1).

Palmer, W. M., Martin, A. P., Flynn, J. R., Reed, S. L., White, R. G., Furbank, R. T., and Grof, C. P. L. (2015). Pea-clarity: 3d molecular imaging of whole plant organs. Scientific Reports, 5, 13492.

Petersen, P. C. and Berg, R. W. (2016). Lognormal firing rate distribution reveals prominent fluctuation-driven regime in spinal motor networks. eLife, 5, e18805.

Petersen, P. C., Vestergaard, M., Jensen, K. H. R., and Berg, R. W. (2014). Premotor spinal network with balanced excitation and inhibition during motor patterns has high resilience to structural division. Journal of Neuroscience, 34(8), 2774-2784.

Phillips, J., Laude, A., Lightowlers, R., Morris, C. M., Turnbull, D. M., and Lax, N. Z. (2016). Development of passive clarity and immunofluorescent labelling of multiple proteins in human cerebellum: understanding mechanisms of neurodegeneration in mitochondrial disease. Scientific reports, 6, 26013.

Poguzhelskaya, E., Artamonov, D., Bolshakova, A., Vlasova, O., and Bezprozvanny, I. (2014). Simplified method to perform CLARITY imaging. Mol Neurodegener, 9, 19.

Renier, N., Wu, Z., Simon, D. J., Yang, J., Ariel, P., and Tessier-Lavigne, M. (2017). idisco: A simple, rapid method to immunolabel large tissue samples for volume imaging. Cell, 159(4), 896-910.

Revelo, N. H., Kamin, D., Truckenbrodt, S., Wong, A. B., Reuter-Jessen, K., Reisinger, E., Moser, T., and Rizzoli, S. O. (2014). A new probe for super-resolution imaging of membranes elucidates trafficking pathways. The Journal of Cell Biology, 205(4), 591-606.

Richardson, D. and Lichtman, J. (2015). Clarifying Tissue Clearing. Cell, 162, 246-57.

Saboor, F., Reckmann, A. N., Tomczyk, C. U., Peters, D. M., Weissmann, N., Kaschtanow, A., Schermuly, R. T., Michurina, T. V., Enikolopov, G., Müller, D., Mietens, A., and Middendorff, R. (2016). Nestin-expressing vascular wall cells drive development of pulmonary hypertension. European Respiratory Journal, 47(3), 876-888.

Schmitz, C., Eastwood, B. S., Tappan, S. J., Glaser, J. R., Peterson, D. A., and Hof, P. R. (2014). Current automated $3 \mathrm{~d}$ cell detection methods are not a suitable replacement for manual stereologic cell counting. Frontiers in Neuroanatomy, 8, 27.

Shah, S., Lubeck, E., Schwarzkopf, M., He, T.-F., Greenbaum, A., Sohn, C., Lignell, A., Choi, H. M., Gradinaru, V., Pierce, N. A., and Cai, L. (2016). Single-molecule rna detection at depth by hybridization chain reaction and tissue hydrogel embedding and clearing. Development, 143(15), 2862-2867.

Silvestri, L., Costantini, I., Sacconi, L., and Pavone, F. S. (2016). Clearing of fixed tissue: a review from a microscopist's perspective. Journal of Biomedical Optics, 21(8), 081205.

Spalteholz, W. (1914). Über das Durchsichtigmachen von menschlichen und tierischen Präparaten und seine theoretischen Bedingungen, nebst Anhang: Über Knochenfärbung. S. Hirzel.

Spence, R. D., Kurth, F., Itoh, N., Mongerson, C. R., Wailes, S. H., Peng, M. S., and MacKenzie-Graham, A. J. (2014). Bringing clarity to gray matter atrophy. NeuroImage, 101, 625-32.

Staudt, T., Lang, M. C., Medda, R., Engelhardt, J., and Hell, S. W. (2006). 2,2/-Thiodiethanol: A new water soluble mounting medium for high resolution optical microscopy. Microscopy Research and Technique, 70(1), 1-9.

Stefaniuk, M., Gualda, E. J., Pawlowska, M., Legutko, D., Matryba, P., Koza, P., Konopka, W., Owczarek, D., Wawrzyniak, M., Loza-Alvarez, P., and Kaczmarek, L. (2016). Light-sheet microscopy imaging of a whole cleared rat brain with Thy1-GFP transgene. Scientific reports, 6, 28209.

Sulkin, M. S., Widder, E., Shao, C., Holzem, K. M., Gloschat, C., Gutbrod, S. R., and Efimov, I. R. (2013). Threedimensional printing physiology laboratory technology. American Journal of Physiology - Heart and Circulatory Physiology, 305(11), H1569-H1573. 
Sung, K., Ding, Y., Ma, J., Chen, H., Huang, V., Cheng, M., Yang, C. F., Kim, J. T., Eguchi, D., Carlo, D. D., Hsiai, T. K., Nakano, A., and Kulkarni, R. P. (2016). Simplified three-dimensional tissue clearing and incorporation of colorimetric phenotyping. Scientific Reports, $\mathbf{6}(1)$.

Susaki, E. A., Tainaka, K., Perrin, D., Kishino, F., Tawara, T., Watanabe, T. M., Yokoyama, C., Onoe, H., Eguchi, M., Yamaguchi, S., Abe, T., Kiyonari, H., Shimizu, Y., Miyawaki, A., Yokota, H., and Ueda, H. R. (2014). Whole-brain imaging with single-cell resolution using chemical cocktails and computational analysis. Cell, 157(3), 726-739.

Sylwestrak, E., Rajasethupathy, P., Wright, M., Jaffe, A., and Deisseroth, K. (2016). Multiplexed intact-tissue transcriptional analysis at cellular resolution. Cell, 164(4), 792-804.

Tainaka, K., Kuno, A., Kubota, S. I., Murakami, T., and Ueda, H. R. (2016). Chemical principles in tissue clearing and staining protocols for whole-body cell profiling. Annual Review of Cell and Developmental Biology, 32(1), 713-741. PMID: 27298088.

Tomer, R., Ye, L., Hsueh, B., and Deisseroth, K. (2014). Advanced CLARITY for rapid and high-resolution imaging of intact tissues. Nat Protoc, 9, 1682-97.

Treweek, J. B., Chan, K. Y., Flytzanis, N. C., Yang, B., Deverman, B. E., Greenbaum, A., Lignell, A., Xiao, C., Cai, L., Ladinsky, M. S., Bjorkman, P. J., Fowlkes, C. C., and Gradinaru, V. (2015). Whole-body tissue stabilization and selective extractions via tissue-hydrogel hybrids for high-resolution intact circuit mapping and phenotyping. Nature protocols, 10(11), 1860-96.

Tyson, A. L., Hilton, S. T., and Andreae, L. C. (2015). Rapid, simple and inexpensive production of custom 3d printed equipment for large-volume fluorescence microscopy. International Journal of Pharmaceutics, 494(2), 651 - 656. The potential for 2D and 3D Printing to Pharmaceutical Development.

Unnersjö-Jess, D., Scott, L., Blom, H., and Brismar, H. (2015). Super-resolution stimulated emission depletion imaging of slit diaphragm proteins in optically cleared kidney tissue. Kidney International, 89(1), 243-247.

van Gastel, N., Torrekens, S., Roberts, S. J., Moermans, K., Schrooten, J., Carmeliet, P., Luttun, A., Luyten, F. P., and Carmeliet, G. (2012). Engineering vascularized bone: Osteogenic and proangiogenic potential of murine periosteal cells. STEM CELLS, 30(11), 2460-2471.

Vestergaard, M. and Berg, R. W. (2015). Divisive Gain Modulation of Motoneurons by Inhibition Optimizes Muscular Control. J Neurosci, 35(8), 3711-3723.

Walloe, S., Nissen, U. V., Berg, R. W., Hounsgaard, J., and Pakkenberg, B. (2011). Stereological estimate of the total number of neurons in spinal segment D9 of the red-eared turtle. J. Neurosci., 31(7), 2431-5.

Wilson, C. J. and Sachdev, R. N. S. (2004). Intracellular and juxtacellular staining with biocytin. Current protocols in neuroscience, Chapter 1, Unit 1.12.

Woo, J., Lee, M., Seo, J. M., Park, H. S., and Cho, Y. E. (2016). Optimization of the optical transparency of rodent tissues by modified PACT-based passive clearing. Experimental \& Molecular Medicine, 48(12), e274.

Xavier, A. L., Fontaine, R., Bloch, S., Affaticati, P., Jenett, A., Demarque, M., Vernier, P., and Yamamoto, K. (2017). Comparative analysis of monoaminergic cerebrospinal fluid-contacting cells in osteichthyes (bony vertebrates). Journal of Comparative Neurology, 525(9), 2265-2283.

Yang, B., Treweek, J., Kulkarni, R., Deverman, B., Chen, C., Lubeck, E., Shah, S., Cai, L., and Gradinaru, V. (2014). Single-cell phenotyping within transparent intact tissue through whole-body clearing. Cell, 158, $945-58$.

Ye, L., Allen, W., Thompson, K., Tian, Q., Hsueh, B., Ramakrishnan, C., Wang, A.-C., Jennings, J. H., Adhikari, A., Halpern, C., Witten, I., Barth, A., Luo, L., McNab, J. A., and Deisseroth, K. (2016). Wiring and molecular features of prefrontal ensembles representing distinct experiences. Cell, 165(7).

Yu, T., Qi, Y., Zhu, J., Xu, J., Gong, H., Luo, Q., and Zhu, D. (2017). Elevated-temperature-induced acceleration of PACT clearing process of mouse brain tissue. Sci Rep, 7, 38848.

Zheng, H. and Rinaman, L. (2016). Simplified CLARITY for visualizing immunofluorescence labeling in the developing rat brain. Brain Struct Funct, 221, 2375-83. 